\title{
International expert consensus on laparoscopic pancreaticoduodenectomy*
}

\author{
Renyi Qin ${ }^{1}$, Michael L. Kendrick ${ }^{2}$, Christopher L. Wolfgang ${ }^{3}$, Barish H. Edil ${ }^{4}$, Chinnusamy Palanivelu ${ }^{5}$, \\ Rowan W. Parks ${ }^{6}$, Yinmo Yang ${ }^{7}$, Jin $\mathrm{He}^{8}$, Taiping Zhang ${ }^{9}$, Yiping Mou ${ }^{10}$, Xianjun Yu ${ }^{11}$, Bing Peng ${ }^{12}$, \\ Palanisamy Senthilnathan ${ }^{5}$, Ho-Seong Han ${ }^{13}$, Jae Hoon Lee ${ }^{14}$, Michiaki Unno ${ }^{15}$, \\ Steven W. M. Olde Damink ${ }^{16}$, Virinder Kumar Bansal ${ }^{17}$, Pierce Chow ${ }^{18}$, Tan To Cheung ${ }^{19}$, Nim Choi ${ }^{20}$, \\ Yu-Wen Tien ${ }^{21}$, Chengfeng Wang ${ }^{22}$, Manson Fok ${ }^{23}$, Xiujun Cai ${ }^{24}$, Shengquan Zou ${ }^{1}$, Shuyou Peng ${ }^{25}$, \\ Yupei Zhao ${ }^{9}$
}

${ }^{1}$ Department of Biliary-Pancreatic Surgery, Affiliated Tongji Hospital, Tongji Medical College, Huazhong University of Science and Technology, Wuhan, China; ${ }^{2}$ Mayo Clinic, Rochester, MN, USA; ${ }^{3}$ Division of Surgical Oncology, Department of Surgery, The John Hopkins University School of Medicine, Baltimore, MD, USA; ${ }^{4}$ Department of Surgery, University of Oklahoma, Oklahoma City, OK, USA; ${ }^{5}$ Department of Surgical Gastroenterology and Hepatopancreatobiliary Surgery, GEM Hospital and Research Centre, Coimbatore, Tamil Nadu, India; ${ }^{6}$ Clinical Surgery, Royal Infirmary of Edinburgh and University of Edinburgh, Edinburgh, UK; ${ }^{7}$ Department of General Surgery, Peking University First Hospital, Beijing, China; ${ }^{8}$ Department of Surgery, Johns Hopkins Medical Institutions, Baltimore, MD, USA; ${ }^{9}$ Department of General Surgery, Peking Union Medical College Hospital, Chinese Academy of Medical Sciences and Peking Union Medical College, Beijing, China; ${ }^{10}$ Department of Gastroenterology and Pancreatic Surgery, Zhejiang Provincial People's Hospital, Hangzhou Medical College, Hangzhou, China; ${ }^{11}$ Department of Pancreatic Surgery, Fudan University Shanghai Cancer Center, Fudan University, Shanghai, China; ${ }^{12}$ Department of Pancreatic Surgery, West China Hospital, Sichuan University, Chengdu, China; ${ }^{13}$ Department of Surgery, Seoul National University College of Medicine, Seoul National University Bundang Hospital, Seoul, Korea; ${ }^{14}$ Division of Hepatopancreatobiliary Surgery, Department of Surgery, Asan Medical Center, Seoul, Korea; ${ }^{15}$ Department of Surgery, Tohoku University Graduate School of Medicine, Sendai, Japan; ${ }^{16}$ Department of Surgery, NUTRIM School of Nutrition and Translational Research in Metabolism, Maastricht University Medical Centre, Maastricht, The Netherlands; ${ }^{17}$ Department of Surgical Disciplines, All India Institute of Medical Sciences, New Delhi, India; ${ }^{18}$ Department of Hepatopancreatobiliary and Transplant Surgery, Singapore General Hospital, Singapore, Singapore; ${ }^{19}$ Department of Surgery, The University of Hong Kong, Queen Mary Hospital, Hong Kong, China; ${ }^{20}$ Department of General Surgery, Hospital Conde S. Januário, Macau, China; ${ }^{21}$ Department of Surgery, National Taiwan University Hospital and National Taiwan University College of Medicine, Taipei; ${ }^{22}$ Department of Pancreatic and Gastric Surgery, National Cancer Center/Cancer Hospital, Chinese Academy of Medical Sciences and Peking Union Medical College, Beijing, China; ${ }^{23}$ Department of Surgery, University Hospital, Macau University of Science and Technology, Macau, China; ${ }^{24}$ Department of General Surgery, Sir Run-Run Shaw Hospital, Zhejiang University, Hangzhou, China; ${ }^{25}$ Department of Hepatopancreatobiliary Surgery, The Second Affiliated Hospital of Zhejiang University School of Medicine, Hangzhou, China

Contributions: (I) Conception and design: R Qin, Y Zhao; (II) Administrative support: R Qin, Y Zhao; (III) Provision of study materials or patients: R Qin, Y Zhao; (IV) Collection and assembly of data: R Qin, C Wang; (V) Data analysis and interpretation: R Qin, Y Zhao, S Peng, S Zou; (VI) Manuscript writing: All authors; (VII) Final approval of manuscript: All authors.

Correspondence to: Renyi Qin. Department of Biliary-Pancreatic Surgery, Affiliated Tongji Hospital, Tongji Medical College, Huazhong University of Science and Technology, Wuhan, China. Email: ryqin@tjh.tjmu.edu.cn; Yupei Zhao. Department of General Surgery, Peking Union Medical College Hospital, Chinese Academy of Medical Sciences and Peking Union Medical College, Beijing, China. Email: zhao8028@263.net.

Members of the Consensus Steering Committee: Renyi Qin, Yupei Zhao, Michael L. Kendrick, Christopher L. Wolfgang, Barish H. Edil, Chinnusamy Palanivelu, Shuyou Peng.

Members of the Consensus Development Committee: Rowan W. Parks, Yinmo Yang, Jin He, Taiping Zhang, Yiping Mou, Xianjun Yu, Bing Peng, Palanisamy Senthilnathan, Ho-Seong Han, Jae Hoon Lee, Michiaki Unno, Steven Olde Damink, Virinder Kumar Bansal, Pierce Chow, Tan To Cheung, Nim Choi, Yu-Wen Tien, Chengfeng Wang, Manson Fok, Xiujun Cai, Shengquan Zhou.

Members of the Consensus Secretary: Junfang Zhao, Hang Zhang, Min Wang.

*From The $1^{\text {st }}$ Summit on Minimally Invasive Pancreatico-Biliary Surgery, Wuhan, China. 
Importance: While laparoscopic pancreaticoduodenectomy (LPD) is being adopted with increasing enthusiasm worldwide, it is still challenging for both technical and anatomical reasons. Currently, there is no consensus on the technical standards for LPD.

Objective: The aim of this consensus statement is to guide the continued safe progression and adoption of LPD.

Evidence Review: An international panel of experts was selected based on their clinical and scientific expertise in laparoscopic and open pancreaticoduodenectomy. Statements were produced upon reviewing the literature and assessed by the members of the expert panel. The literature search and its critical appraisal were limited to articles published in English during the period from 1994 to 2019. The Web of Science, Medline, and Cochrane Library and Clinical Trials databases were searched, The search strategy included, but was not limited to, the terms 'laparoscopic', 'pancreaticoduodenectomy, 'pancreatoduodenectomy', 'Whipple's operation', and 'minimally invasive surgery'. Reference lists from the included articles were manually checked for any additional studies, which were included when appropriate. Delphi method was used to establish expert consensus and the AGREE II-GRS Instrument was applied to assess the methodological quality and externally validate the final statements. The statements were further discussed during a one-day face-to-face meeting at the $1^{\text {st }}$ Summit on Minimally Invasive Pancreatico-Biliary Surgery in Wuhan, China.

Findings: Twenty-eight international experts from 8 countries constructed the expert panel. Sixteen statements were produced by the members of the expert panel. At least $80 \%$ of responders agreed with the majority $(80 \%)$ of statements. Other than three randomized controlled trials published to date, most evidences were based on level 3 or 4 studies according to the AGREE II-GRS Instrument.

Conclusions and Relevance: The Wuhan international expert consensus meeting on LPD has produced a set of clinical practice statements for the safe development and progression of LPD. LPD is currently in its development and exploration stages, as defined by the international IDEAL framework for surgical innovation. More robust randomized controlled trial and registry study are essential to proceed with the assessment of LPD.

Keywords: Consensus; pancreaticoduodenectomy; laparoscopy; Delphi technique

Submitted Apr 24, 2020. Accepted for publication Jul 15, 2020.

doi: $10.21037 / \mathrm{hbsn}-20-446$

View this article at: http://dx.doi.org/10.21037/hbsn-20-446

\section{Introduction}

Laparoscopic pancreaticoduodenectomy (LPD) was first reported by Gagner and Pomp in 1994 (1). Since then, more and more centers started carrying out this procedure not only in pancreatic cancer or periampullary malignancies, but also in benign disease or low-grade malignant neoplasm (2-5). However, LPD is still considered to be a technically demanding procedure because of the extensive dissection around critical anatomical structures and the complex reconstruction $(6,7)$. Although there has been worldwide interest in adopting LPD, its safety and efficacy have not gained uniform acceptance $(6,8,9)$. Most studies revealed favorable outcomes in larger volume centers, but a recent meta-analysis of randomized controlled trials (RCTs) showed that LPD shows no advantage over open pancreaticoduodenectomy (OPD) $(6,10)$. Furthermore, the recent LEOPARD-2 trial reported 90-day mortality was even higher in the LPD group in a cohort of $50 \mathrm{vs}$. 50 patients (11), resulting in a prematurely termination of this project because of safety concerns. Given the fact that increased mortality is not observed in all centers and that LPD is done safely by experienced surgeons in large volume centers (12-14), surgeon experience, learning curve, and annual volume are likely have large influence on the outcome.

Together with LPD, robotic pancreaticoduodenectomy (RPD) forms two major minimally invasive patterns of such complex procedure (15). RPD has been shown as a safe and feasible alternative to conservative pancreaticoduodenectomy in terms of perioperative outcomes (16). Even more, many 
have the belief that RPD is even superior to LPD because of the advantages in digestive tract reconstruction. However, taken into account of increased cost (17) and the fact that RPD is not available in all countries and locations, it is important that some pancreatic centers must necessarily focus on LPD, but not RPD.

The European Association for Endoscopic Surgery consensus statement on LPD reported that it is feasible and safe in experienced hands; however, it should only be considered in selected cases and probably not in low-volume centers (18). While the theoretical benefits of LPD are clear, there is no clear consensus among the surgical community regarding its application. In order to advance $L P D$, an international panel of experts was convened at the $1^{\text {st }}$ Summit on Minimally Invasive Pancreatico-Biliary Surgery in Wuhan, China. The present consensus statement on LPD was developed and aimed to provide guidance for both experienced and training surgeons, as well as for specialist institutions, regarding the appropriateness of care, in order to reduce variations in practice, and to facilitate the safe expansion of LPD with the goal of improving patient care.

We present the following article in accordance with the PRISMA reporting checklist (available at http://dx.doi. org/10.21037/hbsn-20-446.

\section{Methods}

\section{Selection of the expert panel}

The members of the international expert panel were selected by the summit chairman based on their publications in peer-reviewed journals and/or their significant contributions to the development of LPD. To diminish the bias that may cause from participated enthusiastic laparoscopic surgeons in the expert-panel, pancreatic surgeons who do not perform LPD were also invited to construct the panel. Twenty-eight members from eight countries constituted the expert panelists. Twentyone of them attended the one-day face-to-face meeting at the $1^{\text {st }}$ Summit on Minimally Invasive Pancreatico-Biliary Surgery in Wuhan, China, which was held on the date from June $13^{\text {th }}$ to June $15^{\text {th }}, 2019$. Other experts took part in the discussion by e-mail. The global distribution of participated experts is presented in Table S1.

\section{Literature search and appraisal}

The expert panel agreed on the list of topics to be included in the consensus conference. Each expert was assigned two or more topics and asked to prepare evidence-based statements supported by the current literature. The literature search and its critical appraisal were limited to articles published in English during the period from 1994 to 2019. The Web of Science, Medline, and Cochrane Library and Clinical Trials databases were searched, The search strategy included, but was not limited to, the terms 'laparoscopic', 'pancreaticoduodenectomy, 'pancreatoduodenectomy', 'Whipple's operation', and 'minimally invasive surgery'. Reference lists from the included articles were manually checked for any additional studies, which were included when appropriate. Critical appraisal of the literature was carried out using the evidence level provided by the Oxford Centre for Evidence-based Medicine (http://www.cebm.net/oxford-centre-evidencebased-medicine-levels-evidence-march-2009/). Literature search and manual reference lists check were performed by the consensus secretary (JZ, HZ, and MW). Flow chart of the inclusion process is presented in Figure 1.

\section{Selection of the topics}

After a literature review and discussion by the consensus steering committee, five domains including 16 topics were identified: implementation, preoperative preparation, techniques, postoperative management and training. Each domain was further subdivided into certain topics. For example, the "implementation" domain was divided into "safety and feasibility", "hospital volume", "surgeon experience", and "medical team". All topics were sent to all expert panelists who were asked to either accept the statement or modify them. For the latter, a free text option was given to suggest detailed modifications or add new topics. Subjects with less than $80 \%$ agreement were considered inadequate. After the first round of surveys, modifications and additions were applied and a revised survey was sent out. Once consensus was reached, a draft document was compiled and sent out for final approval.

\section{Consensus development}

Upon reviewing the literature, the expert panelists drafted statements on a specific topic accompanied by a supporting discussion. All statements were combined and disseminated to the entire expert panel for voting in accordance with the Delphi methodology. This methodology allowed each expert to either agree or disagree with a given statement and 


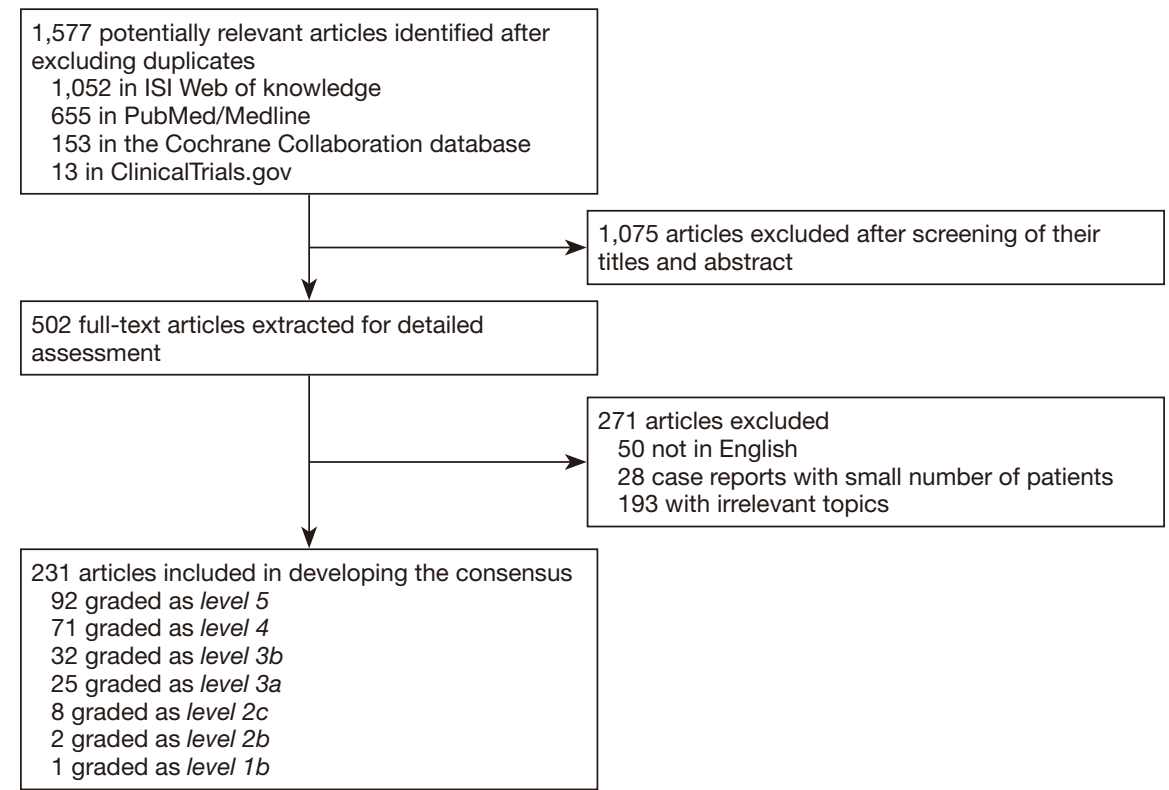

Figure 1 PRISMA diagram. Graphical representation of the publications that were reviewed in the process of generating this consensus statement. Three independent literature searches were performed, with each search including '(pancreatoduodenectomy OR pancreaticoduodenectomy) AND laparoscopic'. Level of evidence was graded according to the Oxford Centre for Evidence-based Medicine from 1 to 5 .

make recommendations for changes to the statement if they consider it necessary. These statements were assessed by the members of the expert panel by email, and all response were sent back to the steering committee (first Delphi round). After statistical analysis, the statements with less than $80 \%$ agreement or new statements suggested by more than two experts were modified and put in circulation for further evaluation (second Delphi round). Based on the comments and suggestions, the consensus steering committee decided on the final statements and composed the first draft. The first draft was sent to all the experts who provided their responses by email. All statements were approved at a oneday face-to-face meeting held at the $1^{\text {st }}$ Summit on Minimally Invasive Pancreatico-Biliary Surgery in Wuhan, China. The final version of the manuscript was reviewed and approved by all participants involved in developing this statement. Of each statement, the quality of evidence and strength of recommendation were assessed applying GRADE approach. A summary of these topics, statements, quality of evidence, and recommendations is presented in Table $S 2$.

\section{Grading of evidence and definitions}

After data extraction, the teams created a presentation on their topic and drafted a more comprehensive text summary of their findings. This process was conducted according to two validated methods: the Delphi method (for establishing expert consensus) and the AGREE IIGlobal Rating Scale (GRS) Instrument (for the assessment of methodological quality and external validation of the final statements) (19). The final version of the manuscript was reviewed and approved by all experts involved in developing a final statement. We should be aware that with Delphi methodology, the sample size of participated experts was relatively small, which may result in potential bias when selecting topics and making statements, however, all topics were open for full discussion within the steering committee, and statements were drew based on evidence in literature.

\section{Statistical analysis}

Data collected during each round of the survey were analyzed for internal consistency using Cronbach's alpha. Medians and interquartile ranges of responses from panel members were calculated for all survey items. Responses to items on a categorical scale (yes/no) were analyzed as percentage responses. Statistical analysis was performed 
using SPSS version 20.0 (IBM Corp., Armonk, NY, USA).

\section{Results}

\section{Section 1: Implementation}

\section{Topic 1: Safety and feasibility}

Statement: LPD is safe and feasible compared with OPD, when performed in large volume medical centers by experienced surgeons. LPD is associated with a longer operative time, less intraoperative blood loss, and shorter length of stay (LOS) than OPD, while its overall complication and perioperative mortality rates are equivalent.

Quality of evidence: Moderate.

Strength of recommendation: Strong.

In 1994, Gagner and Pomp reported their first experience in performing LPD, and concluded that laparoscopic Whipple procedure was technically feasible, but may not improve the postoperative outcome or shorten the postoperative recovery period (1). Since then, an increasing number of LPD have been subsequently carried out and their safety and feasibility have continued to be discussed.

Some studies have shown that LPD may be either less safe or confers no advantage over OPD. Cuschieri reported his disappointing experience with LPD for periampullary cancer and did not observe any benefit from this approach (20). Dokmak et al. found that LPD was associated with higher morbidity in a series of 46 patients with a higher incidence of severe postoperative pancreatic fistula (POPF) (28\% vs. $20 \%, \mathrm{P}=0.32)(21)$. van Hilst et al. reported that, although not statistically significant, LPD was associated with more complication-related deaths than OPD [5/50 (10\%) patients in the LPD group vs. $1 / 49(2 \%)$ in the OPD group; risk ratio, $4.90 ; 95 \%$ confidence interval (CI), 0.59-40.44; $\mathrm{P}=0.20]$. Furthermore, there was no difference between groups in time to functional recovery in their multicenter RCT (11). As the operative technique continued to develop and more cases were accumulated, an increasing amount of data demonstrated that LPD was not inferior to OPD. Nickel et al. reported no significant difference in 90-day mortality, Clavien-Dindo grade $\geq \mathrm{III}$ complications, LOS, POPF, delayed gastric emptying (DGE), postpancreatectomy hemorrhage (PPH), bile leak, reoperation, readmission, or oncologic outcomes between LPD and OPD (6). Ausania et al. found no statistically significant differences between LPD and OPD in terms of postoperative complications and mortality (13). Stauffer et al. reported that LPD provided similar short-term outcomes and long-term survival to OPD in the treatment of pancreatic ductal adenocarcinoma (PDAC) (22).

In recent years, the vast majority of studies conducted at high-volume centers demonstrated that LPD is feasible, safe and effective. Palanivelu et al. showed that LPD allowed a shorter LOS than OPD (7 vs. 13 days; $\mathrm{P}=0.001$ ) (14). This trial was closely followed by a study from Poves et al. that demonstrated LPD was associated with a shorter LOS (median 13.5 vs. 17 days; $\mathrm{P}=0.024$ ) and a more favorable postoperative course than OPD while maintaining the oncological standards of a curativeintent surgical resection (8). A systematic review and meta-analysis showed that LPD was associated with longer disease-free survival than OPD (23). Chen et al. found that the 3 -year [odds ratio (OR), $1.50 ; 95 \% \mathrm{CI}$, 1.12-2.02; $\mathrm{P}=0.007$ ], 4-year (OR, 1.73; 95\% CI, 1.02-2.93; $\mathrm{P}=0.04)$, and 5 -year overall survival (OR, 2.11; $95 \% \mathrm{CI}$, 1.35-3.31; $\mathrm{P}=0.001)$ were significantly longer in the LPD group compared with the OPD group (24). Meng et al. reported that LPD was a feasible, safe, and effective method for the treatment of non-pancreatic periampullary adenocarcinoma and may be preferable to OPD (25). Klompmaker et al. affirmed the effectiveness and safety of LPD in a multinational, propensity-matched comparative study (7). All in all, LPD is feasible and safe in experienced hands.

\section{Topic 2: Volume of pancreatic center and LPD}

Statement: LPD should be carried out in pancreatic center with at least 25 cases of OPD per year. In addition, a robust radiology department and experienced interventionalists, as well as the pathology and anesthesiology departments, should also work closely together in order to carry out the surgery successfully.

Quality of evidence: Moderate.

Strength of recommendation: Strong.

Although the safety and feasibility of LPD are becoming increasingly accepted, it is not recommended that all hospitals routinely perform LPD surgery. In a comparative study of patients who underwent OPD $(n=14)$ and LPD $(n=14)$ for benign and malignant indications at a single institution, Zureikat et al. concluded that LPD could be safely and feasibly implemented at a high-volume pancreatic surgery center without subjecting patients to an unacceptably higher risk of complications or compromising oncologic surgical principles (26). Qin et al. performed 
a meta-analysis and suggested that LPD should only be performed at high-volume pancreatic surgery centers (27). Kutlu et al. investigated the relationship between the hospital volume of LPD and morbidity, mortality, and oncologic quality using the American National Cancer Data Base. They confirmed that the risk of postoperative mortality and suboptimal oncologic quality following LPD are higher in low-volume hospitals, and suggested that the putative benefits of LPD are likely to be observed in institutions performing $\geq 25$ PD per year (28). In another large American National Cancer Data Base study of 4,421 patients who underwent OPD $(4,067,91 \%)$ and LPD (384, $9 \%)$, Sharpe et al. concluded that higher hospital volume was associated with a lower risk of 30-day mortality. In institutions that performed $\geq 10 \mathrm{LPD}$, the 30 -day mortality rate of the laparoscopic approach was equal to that of the open approach (29). Wang et al. reviewed 1,029 LPD and concluded that higher hospital and surgeon volume, as well as surgeon experience with minimally invasive surgery, were associated with a lower risk of surgical failure (defined as a composition of 30-day mortality, conversion to laparotomy and postoperative complications with Clavien-Dindo $\geq$ III) (12). Klompmaker et al. performed a retrospective propensity score-matched study of minimally invasive pancreaticoduodenectomy (MIPD) across 14 European centers. In centers performing $\geq 10$ MIPD annually, no differences were found in major morbidity, mortality, and LOS between LPD and OPD (7). In a systematic review of 26 MIPD and OPD comparative trials, Kendrick et al. reported that an excessive mortality after MIPD was associated with low-volume ( $<5 \mathrm{MIPD} /$ year) hospitals. Among hospitals performing $\geq 5 \mathrm{MIPD} /$ year, there were no mortality after MIPD, which was similar to the outcome of OPD (30). Senthilnathan et al. summarized their 15-year experience and reported that LPD has the potential to become the standard of care for patients with selected periampullary and pancreatic head tumors with acceptable oncological outcome, especially at high-volume centers (31). In general, it is recommended that LPD is restricted to high-volume centers, not only for the surgical experience, but also for the availability of multidisciplinary care.

\section{Topic 3: Surgeon's experience and LPD}

Statement: In order to perform LPD successfully, surgeons should meet the following criteria: (I) Surgeons should have advanced laparoscopic skills. Advancement through the learning curve of minimally invasive surgery from basic to complex procedures, and mastering basic laparoscopic skills, such as dissection, suturing, and knotting, is essential before starting to perform LPD. (II) Experienced in OPD. Surgeons and teams intending to adopt LPD should first be proficient in OPD with each individual having a cumulative experience of $>50$ cases.

Quality of evidence: Moderate.

Strength of recommendation: Strong.

In addition to the volume of the medical center, the surgeon's experience and laparoscopic skills make an important contribution to performing LPD successfully. Sharpe et al. demonstrated a two-fold increase in the rate of perioperative mortality compared with OPD among surgeons performing $<10$ LPD within 2 years. These results may be attributed to the early learning curve in these surgeons (29). Hence, before performing LPD, surgeons should obtain structured training, carefully plan and consider the type of surgery, to minimize the risk to the patients $(32,33)$. Wang et al. concluded that the criteria for credentialing surgeons to perform LPD should have more experiences not only in OPD, but also minimally invasive surgery in general. In fact, experience in minimally invasive surgery was the only factor associated with operative failure (12). Nagakawa et al. concluded that surgeons need more than 30 cases to achieve a stable performance for LPD. They particularly commented that procedures requiring more demanding skills, such as radical lymph node dissection, should be avoided during the introductory period (34). Coelho et al. advocated that LPD procedures should be performed by surgeons with extensive experience in open and laparoscopic biliary and pancreatic surgery (35). Kendrick et al. concluded that LPD with major venous resection is also feasible in selected patients, if extensive experience with complex laparoscopic pancreatic resection and reconstruction has been gained before attempting this procedure (36). Later, the same group reported that it was important to have performed at least 50 OPD prior to embarking in MIPD. However, it was also mentioned that at a few high-volume centers with formal MIPD training programs, the required OPD volume may be significantly less (30).

\section{Topic 4: Surgical team and LPD}

Statement: The operating surgeon, assistant surgeon, anesthesiologist, and nursing team for LPD should be relatively fixed.

Quality of evidence: Low.

Level of recommendation: Weak.

Currently, there are no studies focusing on whether change in the composition of the surgical team impacts the 
effectiveness of surgery between LPD and OPD. However, in general, better familiarity and expertise seemed to related with shorter operative time $(37,38)$. Therefore, a stable surgical team, including operating and assistant surgeons, nurses, and anesthesiologist, who can work together consistently, is recommended. This could overcome the learning curve in a shorter period of time (39-41). In addition, two-operative surgeon model has been shown as a safe and feasible alternative to conventional operativeassistant surgeon model in LPD (42).

\section{Section 2: Indications, contraindications, and preoperative preparation}

\section{Topic 5: Indications}

Statement: Indications of LPD could be similar to those of OPD, and should be determined by a multidisciplinary team (MDT) discussion before surgery, with careful consideration of the stage of the learning curve at which the surgeon is located.

Quality of evidence: Moderate.

Strength of recommendation: Strong.

Postoperative outcomes after LPD are obviously associated with a learning curve (12). Thus, it is recommended to conduct a MDT discussion before surgery to identify the indications of LPD (43-46). According to the stage of the learning curve, the following case selection and stepwise expansion of surgical indications are proposed $(6,34,47)$ : (I) in the initial period of the learning curve: after extensive simulation and step-by-step training, periampullary tumors with a clear tissue structure and no vascular compression should be selected. Patients should have no history of previous upper abdominal surgery and have lower body mass index $\left(\mathrm{BMI} \leq 25.0 \mathrm{~kg} / \mathrm{m}^{2}\right)$. For total LPD, it is recommended to select patients with a pancreatic duct diameter $\geq 3 \mathrm{~mm}$ and a bile duct diameter $\geq 10 \mathrm{~mm}$; (II) in the technical competency period: it is recommended that tumors around the ampulla without vascular invasion are selected, as well as benign pancreatic tumors without vascular compression; (III) in the challenging cases period: the indications for LPD can be gradually expanded to mirror those of OPD since the surgeons are considered to have fully overcome the learning curve by this period. For instance, for LPD with venous resection and reconstruction: although only reported in a small number of patients, these cases should only be considered by an experienced minimally invasive surgical team to achieve good longterm outcomes in well-selected patients (48). Wang et al. classified the pancreatic head cancer into eight types with the aim of guiding surgeons in making the optimized operative decisions (49), although it is of interest to apply this system in the guidance of selecting more appropriate cases for LPD, this still need to be further studied in a prospective cohort.

Apart from strict control of indications, standardized training and education should be guaranteed to ensure safe and stable development of LPD (50). In selected patients, LPD in the hands of experienced surgeons offers advantages over open surgery without compromising the oncologic principles (51). With improvement in LPD technique, the indications will be extended to patients with vascular invasion. For LPD with venous resection and reconstruction, vascular grafts are more frequently needed, because adequate mobilization is not easy to be performed under laparoscopy, and vascular grafts can facilitate the safe reconstruction (2).

Wang et al. reported that the cases who proceeded to laparoscopic surgery should fulfill the following criteria: tumor diameter $<4 \mathrm{~cm}$, with no signs of peripheral vascular invasion, distant metastasis, or evident lymph node swelling (52). Bausch and Keck agreed that LPD is in particular suitable for the treatment of benign or premalignant tumors of the pancreatic head (5). Another group selected patients for LPD who met the following criteria: (I) $\mathrm{BMI}<28.0 \mathrm{~kg} / \mathrm{m}^{2}$; (II) ampullary tumors, duodenal tumors restricted to the second part of the duodenum, lower common bile duct tumors, and PDAC of the pancreatic head; (III) chronic pancreatitis with mass in the pancreatic head and poor response after conservative treatment; and (IV) resectable, based on evaluation of professional radiologists and experienced surgeons thorough assessment of preoperative radiology (53).

\section{Topic 6: Contraindications}

Statement: Contraindications of LPD could be similar to those of OPD, in addition to some laparoscopic contraindications.

Quality of evidence: Moderate.

Strength of recommendation: Weak.

Besides the invasive extent of malignancy, the contraindications of LPD included morbid obesity (BMI $\geq 40 \mathrm{~kg} / \mathrm{m}^{2}$ ) (54-57), particularly unusual anatomy (e.g., a duodenum and pancreatic head residing in the true pelvis), and previous surgery with documented extensive adhesive disease (frozen abdomen) (39). Moreover, LPD is also contraindicated in patients that are deemed by the 
MDT to be incapable of tolerating the anesthesia for pneumoperitoneum (such as those with severe chronic hepatic, renal, pulmonary, or cardiac disease) (58-60).

After thorough training and accumulation of surgical experience, the contraindications to LPD will likely be adjusted to mirror those of OPD (18). For instance, patients with metastatic disease (10,61-65); those with acute or chronic pancreatitis, widespread adhesions in the abdominal cavity, difficulty in exposing and separating the pancreas, or failure of establishing pneumoperitoneum (61-65); and those with lesions over than 180 degrees of superior mesenteric artery encasement, any celiac abutment, unreconstructible superior mesenteric vein/portal occlusion, or aortic invasion or encasement $(7,15,25,36,59,60,66)$. It should be kept in mind that cases that are considered candidates for LPD at the late stage of learning curve may not be suitable in the early period.

\section{Topic 7: Preoperative preparation}

Statement: The preoperative preparation for LPD patients are consistent with those for OPD patients. Surgeons per se should also be prepared with proficient surgical skills for reducing the rate of conversion to laparotomy.

Quality of evidence: Moderate.

Strength of recommendation: Strong.

In terms of general assessment, patients must be examined to ensure that they have no obvious heart, lung, kidney, or other major organ dysfunction, and no obvious surgical contraindications. Before surgery, any anemia, hypoalbuminemia, and acid-base or metabolic disorders should be corrected, and nutritional status should be optimized. The decision to perform preoperative biliary drainage for jaundice is at the discretion of each center $(28,67)$. Neoadjuvant chemotherapy is considered and administered according to the same principles as OPD (68).

Careful examination of local lesions with imaging studies (including ultrasound, multi-phase contrast-enhanced CT, and MRI, etc.) is necessary to comprehensively understand the tumor size, location, relationship with peripheral blood vessels, and whether there are vascular variations (especially of the proper hepatic artery). For patients with an uncertain diagnosis, endoscopic ultrasound-guided biopsy, positron emission tomography-CT, and other further investigations should be considered. Although carrying out the relevant preoperative investigations to obtain a pathological diagnosis has been advocated, a definitive pathological diagnosis before surgery is not required (69).

The principle of conversion from LPD to OPD including reasons of active or passive. Apart from adequate preparations of operated patients, surgeons per se should be prepared with proficient surgical skills by overcoming learning curve with the aim of reducing rate of active/ passive conversion to laparotomy, because postoperative outcomes after LPD were obviously associated with a learning curve (12), and patients who have a conversion often have a poorer prognosis than totally LPD.

\section{Section 3: Technique}

\section{Topic 8: Types of LPD}

Statement: There are four types of LPD: Total, handassisted, laparoscopy-assisted, and robotic-assistance. Each is defined below. The choice of operative approach should be made in accordance with the stage of learning cure at which the surgeon is located. Robotic surgery for LPD may offer several advantages, especially for digestive tract reconstruction. However, due to its high cost, it is not widely utilized.

Quality of evidence: Moderate.

Strength of recommendation: Strong.

LPD includes (I) total LPD, where both resection and gastrointestinal reconstruction are completed laparoscopically; (II) hand-assisted LPD (HALPD), where a hand port or a mini-incision is added to facilitate the procedure; (III) laparoscopy-assisted PD (LAPD), in which dissection is performed laparoscopically and reconstruction is completed through a small mini-laparotomy incision; and (IV) robotic-assisted pancreaticoduodenectomy (RAPD), where dissection is performed laparoscopically and reconstruction is completed using the surgical system $(62,70)$.

Total LPD is the most common type of LPD. Its limitations can be attributed to the complexity of performing gastrointestinal reconstruction laparoscopically. To overcome these shortcomings, HALPD and LAPD are recommended, and can serve as a bridge from open to laparoscopic surgery during the learning curve (71). Robotic assistance surgery theoretically offers several advantages, including a clear, three-dimensional image, high magnification of the operation field, and flexible arms and wrists. There is increasing evidence that RAPD can be performed safely in selected patients, but there is no definitive proof that it translates into reduced morbidity, mostly because of the unsolved problem of $\operatorname{POPF}(72,73)$. Zhao et al. found that RAPD is a safe and feasible alternative to OPD in terms of perioperative outcomes. However, 
due to the lack of high-quality RCT, the evidence is still limited (16). Zhang et al. reported that both LPD and RAPD were technically feasible and had comparable shortterm results in experienced hands. There are steep learning curves for both LPD and RAPD. However, the learning curve of RAPD seems shorter. And large-scale clinical trials are still needed to compare the long-term outcomes of LPD and RAPD (17). The current evidence suggested that robotic approach has a longer operative time and higher costs compared with the laparoscopic approach (17).

\section{Topic 9: The approach to resection during LPD}

Statement: The principles of tumor resection by LPD should be similar to those of standard OPD for different types of cancer. Short-term oncologic outcomes (harvested lymph nodes/positive resection margins) are comparable between LPD and OPD.

Quality of evidence: Moderate.

Strength of recommendation: Strong.

Data on the oncologic outcomes of LPD are insufficient. Of five meta-analyses focusing on minimal invasive pancreaticoduodenectomy and OPD, only two found significant differences in terms of the total number of harvested lymph nodes and the rate of positive resection margins $(10,74)$. Correa-Gallego et al. reported more lymph nodes harvested and a higher rate of negative margins following MIPD (74), whereas de Rooij and co-workers found no differences in the total number of retrieved lymph nodes but observed a lower rate of positive margins in the minimal invasive pancreaticoduodenectomy group (10). Poves $e t a l$. and Palanivelu $e t a l$. also demonstrated that there was no significant difference in the number of lymph nodes retrieved or resection margins between the two approaches $(8,62)$. Two comparative studies reported that a greater number of lymph nodes were retrieved during LPD (75). Croome et al. found that LPD was more effective in securing surgical margins than OPD in patients requiring major vascular resection (75). Cai et al. and Palanisamy et al. suggested that major venous resection and reconstruction can be performed safely by LPD (66,76). In a matched case-control study, Song et al. found no differences in survival among patients with periampullary cancer that underwent LPD or OPD (77). Palanivelu et al. reported a 5 -year survival of $32 \%$ in patients with periampullary cancer following LPD (62). Another study from the same center reported 5 -year survival of $29.4 \%$ in patients with PDAC (31). However, both studies included only patients with early-stage cancer (T1-2, N0-1, M0). Comparative studies of LPD and OPD for PDAC found no statistically significant differences in survival $(78,79)$. These findings were subsequently confirmed by Croome et al. (75).

\section{Topic 10: Gastrointestinal reconstruction during LPD}

Statement: The reconstruction phase during LPD is especially technically demanding and time-consuming, taking longer than that during OPD. However, the morbidity associated with gastrointestinal reconstruction is comparable between LPD and OPD.

Quality of evidence: Moderate.

Strength of recommendation: Strong.

LPD often takes significantly longer operating time than $\operatorname{OPD}(12,13,80)$. A previous meta-analysis found no difference between LPD and OPD in terms of overall morbidity associated with gastrointestinal reconstruction, such as the rates of POPF and clinically relevant POPF, bile or gastrointestinal leakage (13). On the other hand, de Rooij et al. reported a significantly lower rate of delayed gastric empty after LPD (10). Some comparative studies also reported similar morbidity $(77,80,81)$ and POPF rates after LPD and OPD (77,80-83). However, Dokmak et al. observed significantly more grade C POPF in the laparoscopic group (21).

Management of the pancreatic stump is the most complicated step during digestive tract reconstruction. Although pancreaticojejunostomy (PJ) is more commonly performed than pancreaticogastrostomy, many surgeons have the belief that both PJ and pancreaticogastrostomy were safe reconstructive approaches, and that the choice between them would depend on preference of surgeons (84). Two-layer duct-to-mucosal anastomosis is the most common form of PJ, but other modified methods have also been reported, including single-row, invaginated, dunking, sleeving-joint, end-to-end, and binding PJ (7,85-90). Some modifications of duct-to-mucosal PJ were associated with reduced rates of POPF and postoperative complications, for instance, Blumgart anastomosis $(83,91)$ and Bing's anastomosis (90). Similarly, certain modifications of pancreaticogastrostomy were also shown as safe and feasible procedures $(92,93)$.

Several techniques that do not involve suturing of the main pancreatic duct to the mucosa of the jejunum, which may shorten the PJ time, have been reported, and larger prospective cohort series and RCTs are warranted to validate them (94). Lu et al. reported that end-to-end PJ was associated with a low rate of pancreatic leakage, while none of the patients who underwent a duct-to-jejunal end- 
to-side embedding PJ developed leakage (87). Hughes et al. presented a less technically demanding PJ technique that creates an end-to-end intussuscepting anastomosis using a running monofilament suture (89). Nakamura et al.'s method of PJ with closure of the pancreatic stump by an endoscopic linear stapler was shown to be feasible during LPD with positive short-term results (95). Kim et al. demonstrated that their novel technique of PJ using only two transpancreatic buttress sutures is a simple method suitable for total LPD, which can reduce the burden on the surgeon and achieve a secure anastomosis (85). Hong's single-stitch duct-to-mucosa PJ could not only reduce the incidence of clinically relevant POPF, but also shorten the operation time (96). The imbedding duct-to-mucosa PJ was found to be a simple and safe reconstruction approach in a series of patients reported by Wang et al., especially in patients with a nondilated pancreatic duct (94). Lei et al. demonstrated that their asymmetric sleeving-joint technique facilitated PJ, both laparoscopically and during open surgery (88).

\section{Section 4: Postoperative management and follow-up}

\section{Topic 11: Postoperative morbidity}

Statement: LPD, although complicated and technically demanding, is safe and effective in the hands of experienced surgeons. The rate of complications in patients who undergo LPD is equivalent to those who undergo OPD. Moreover, patients benefit from the laparoscopic approach with respect to reduced blood loss and surgical site infections, and a shortened hospital stay.

Quality of evidence: High.

Strength of recommendation: Strong.

The precise differences in postoperative morbidity between LPD and OPD remain controversial, with most studies reporting comparable rates. Meta-analysis of the only three RCTs performed showed that there were no significant differences in 90-day mortality, Clavien-Dindo grade $\geq$ III complications, LOS, POPF, DGE, PPH, bile leak, reoperation, readmission, or oncologic outcomes between LPD and OPD. Operation time was significantly longer, but blood loss was less with LPD (median difference, $-151 \mathrm{~mL}$; $95 \% \mathrm{CI},-168.5$ to $-133.4 \mathrm{~mL}$ ), although the certainty of evidence was moderate to very low (6). A previous meta-analysis of retrospective studies also showed that the rate of overall morbidity, POPF, reoperations, DGE, and PPH, were comparable between LPD and OPD $(74,97)$.
A recent study by van Hilst et al. showed that the complication rate after LPD was equivalent to that after OPD, with similar functional recovery time (median, 10 vs. 8 days, $\mathrm{P}=0.80$ ), and Clavien-Dindo grade III or higher complications rate (25 of 50 patients $v s .19$ of 49 patients, $\mathrm{P}=0.26)(11)$. There were similar findings in two other studies $(8,14)$. In terms of the most major complications, such as POPF, DGE, and PPH, most of the research showed that there was no significant difference between the different procedures. Song et al. found comparable POPF and DGE rates in a matched case-control cohort study comparing laparoscopic and open pyloruspreserving pancreaticoduodenectomy in patients with periampullary tumors (77). Liang et al. reported that the major complication (Clavien-Dindo $\geq \mathrm{III}$ ) rates were not significantly different ( $33 \%$ for LPD vs. $17 \%$ for OPD), but a trend towards more re-operations after LPD was found when compared with OPD ( $20 \%$ vs. $3 \% ; \mathrm{P}=0.07)$ (98). Compared to OPD, LPD took longer time to perform, but no differences in blood loss, morbidity, mortality, R0 resection rate, and lymph node harvest were noted (98). Kuesters et al. also found no difference in postoperative mortality and morbidity between LPD and OPD in their study, however, patients in the LPD group tended to have a lower BMI (23 vs. $\left.27 \mathrm{~kg} / \mathrm{m}^{2}, \mathrm{P}<0.001\right)$ and a greater proportion had a soft pancreas $(57 \%$ vs. $47 \%, \mathrm{P}=0.38)$, but there were no differences in associated comorbidities or underlying disease (59). Similarly, Jiang et al. showed no significant difference in operative time, intraoperative blood loss, the rate of conversion to OPD, postoperative complications, mortality, or the number of lymph nodes retrieved during surgery for malignancy (99).

Moreover, compared with OPD, LPD has beneficial effects on wound healing, as evidenced in a decreased surgical site infection rate $(39,100)$. Total LPD was associated with lower rates of intra-abdominal abscess $(0 \%$ vs. $16.0 \%, \mathrm{P}=0.049$ ), but there were no differences in POPF, bile leak, DGE, wound infection, LOS, and readmission (all $\mathrm{P}>0.05$ ) (101). In contrast, some studies showed that LOS was shorter in the LPD group $(29,74,77,102)$. LPD was also associated with a reduced blood loss (74), which was confirmed in two independent meta-analysis $(82,102)$. Although not statistically significant, Dokmak et al. reported that both mortality $(2.1 \%$ vs. $0 \%, \mathrm{P}=0.28)$ and severe morbidity were higher in the LPD group (28\% vs. $20 \%$, $\mathrm{P}=0.32$ ), due to the higher incidence of grade $\mathrm{C}$ POPF ( $24 \%$ vs. $6 \%, \mathrm{P}=0.007)$, bleeding ( $24 \%$ vs. $7 \%, \mathrm{P}=0.02)$, and revision surgery $(24 \%$ vs. $11 \%, \mathrm{P}=0.09)(21)$. In a meta- 
analysis of 1,196 patients with LPD and 8,247 with OPD from 11 identified studies, the pooled data showed that LPD was associated with less morbidity, less blood loss, shorter LOS, while comparable POPF and overall survival rates to OPD. As regards postoperative complications, LPD was associated with reduced rates of clinically relevant grade $\mathrm{B} / \mathrm{C}$ POPF (15\% vs. 36\%; $\mathrm{P}=0.036)$ and grade $\mathrm{B} / \mathrm{C}$ DGE ( $8 \%$ vs. $20 \% ; \mathrm{P}=0.049$ ) (103). A comparative study has suggested that LPD is associated with decreased blood loss, longer operative time, similar post-operative complication rate, decreased pain, and shorter LOS, and there was no difference in the incidence of POPF, blood loss, return to diet and lymph node harvest (97). However, another metaanalysis found that laparoscopic pylorus-preserving $\mathrm{PD}$ was associated with a shorter $\operatorname{LOS}(\mathrm{P}=0.0003)$ and a tendency towards lower rates of DGE, although with a longer operation time $(\mathrm{P}=0.02)$ (104). Furthermore, minimally invasive approaches were associated with significantly decreased morbidity in early stage tumors (stage zero-II) (51.3\% vs. $56.2 \%, \mathrm{P}=0.03$ ) and advanced stage disease (stage III-IV) (50\% vs. $60.3 \%, \mathrm{P}=0.04)$ (105). The rate of major postoperative complications (Clavien-Dindo $\geq \mathrm{III}$ ) was $29 \%$ after LPD and $31 \%$ after OPD [relative risk (RR), 0.80; 95\% CI, 0.36-1.79; $\mathrm{P}=0.592]$.

Unless performed by highly skilled surgeons (106), LPD generally required a longer operative time than OPD $(10,29,67,74,77,107)$. Chen et al. reported that while the operative time was longer for LPD (weighted mean difference $87.68 \mathrm{~min}$; 95\% CI, 27.05-148.32; $\mathrm{P}<0.01$ ), the $\mathrm{R} 0$ rate tended to be higher (OR, 1.17; 95\% CI, 1.00-1.37, $\mathrm{P}=0.05)$ and there tended to be more lymph nodes retrieved (weighted mean difference 1.15 ; $95 \%$ CI, -0.16 to -2.47 , $\mathrm{P}=0.08)$, but these differences failed to reach statistical significance (82). These findings confirm that the risks of postoperative mortality and suboptimal oncologic quality are higher at low-volume hospitals. Furthermore, these risks are more profound with LPD compared with OPD. These data suggest that the putative benefits from LPD are unlikely to be observed at institutions performing less than 25 PD per year (28). In an overall analysis of a cohort of patients, POPF was more common after LPD, but it should be noted that the proportion of ampullary adenocarcinoma ( $25 \%$ vs. $10 \%, \mathrm{P}=0.004)$ and soft pancreatic parenchyma ( $52 \%$ vs. $38 \%, \mathrm{P}=0.001$ ) were also higher in that group. After matching ( $\mathrm{n}=65)$, LPD was found to be associated with longer operative time (429 vs. $328 \mathrm{~min}, \mathrm{P}<0.001)$ and less blood loss (370 vs. $515 \mathrm{~mL}, \mathrm{P}=0.047)$. The rate and severity of POPF were similar $(33 \%$ vs. $27 \%, \mathrm{P}=0.439$ and $\mathrm{P}=0.083)$ in the two matched groups. However, both total $(78 \%$ vs. $71 \%, \mathrm{P}=0.030)$ and major complications ( $40 \%$ vs. $23 \%, \mathrm{P}=0.033$ ) were more frequent in the $\mathrm{LPD}$ group. Patients that underwent LPD experienced more postoperative bleeding ( $21 \%$ vs. $14 \%, \mathrm{P}=0.025)$ than those who underwent open surgery. In a multivariate analysis, perioperative transfusion (OR, 5; 95\% CI, $1.5-16$; $\mathrm{P}=0.008$ ), soft pancreas (OR, 2.5; 95\% CI, 1.4-4.6; $\mathrm{P}=0.001$ ), and ampullary adenocarcinoma (OR, 2.6; 95\% CI, 1.2-5.6; $\mathrm{P}=0.015)$ were identified as independent risks factors for major complications (108).

Study dedicated into illuminating the advantage of applying enhanced recovery after surgery (ERAS) in LPD has not be seen in literature so far. However, it has been reported that laparoscopic digestive system surgery within an ERAS protocol led to better immunity preservation (109), faster postoperative rehabilitation, shorter LOS and lower rate of postoperative complications (110). Therefore, further study on this important topic is needed.

\section{Topic 12: Postoperative mortality}

Statement: The mortality rate after LPD is a significant safety concern. Therefore, LPD should only be performed by skilled laparoscopic surgeons with proper training in high-volume pancreatic centers. Further large trials involving well-trained laparoscopic surgeons at high-volume hospitals are needed to clarify this concern.

Quality of evidence: Moderate.

Strength of recommendation: Strong.

A recent meta-analysis of $\mathrm{RCT}$ reported that complication-related mortality occurred in $5 \%$ of the LPD group and $4 \%$ of the OPD group (RR, 1.22; 95\% CI, 0.198.02; $\mathrm{P}=0.841)$ (13). However, in a retrospective analysis of a large dataset, LPD was shown to be as associated with increased 30-day mortality ( $\mathrm{OR}, 1.89 ; \mathrm{P}=0.009)$, although the authors highlighted that this observation could be driven by a surmountable learning curve (29). Moreover, although the differences were not statistically significant, a recent trial by van Hilst $e t$ al. revealed that 90-day mortality after LPD was higher than after OPD (5 of $50 v s .1$ of 49; RR 4.9, 95\% CI, 0.59-40.44; $\mathrm{P}=0.20$ ) (11), pointing out the safety concerns related to the mortality risk of LPD. However, this trial involved surgeons who had performed 20 or more LPD, while the common consensus in literature is that the learning curve for LPD is generally $30-50$ cases $(12,34,61,111,112)$, and $20 \mathrm{LPD}$ may not be sufficient to qualify a surgeon to perform the procedure to the required standard. On the other hand, a 
recent trial by Palanivelu et al. showed that the mortality rate after LPD was equivalent to that after OPD (1 of 32 in each) (14). Hakeem et al. reviewed 12 matched LPD and OPD patients and found that the overall mortality rate was similar ( $3 \%$ vs. $6 \%, \mathrm{P}=0.283$ ), with only one death within 30 days in the OPD group (secondary to severe sepsis) and none in the LPD group (78). Torphy et al. analyzed 22,013 patients in the American National Cancer Database who had undergone pancreaticoduodenectomy between 2010 and 2015. Among these, 3,205 patients had undergone LPD, and the authors found no significant difference in 30or 90-day mortality between LPD and OPD (9). Kuesters et al. found no significant difference in postoperative mortality and morbidity between LPD and OPD in their series of patients with PDAC (59). Similarly, Khaled et al. also found no significant difference in postoperative mortality ( $0 \%$ vs. $6.7 \%, \mathrm{P}=0.99)$ between OPD and LPD in a cohort of 30 matched patients (15 LPD vs. 15 OPD) (51). LPD is a very difficult and risky operation, but $\mathrm{Lu}$ et al. indicated that if hospitals have ample clinical experience in traditional pancreaticoduodenectomy, up-to-date laparoscopic equipment, and strict surgical indications, and if the surgeons have meticulous laparoscopic technique and a culture of consultation and cooperation, LPD can be feasible and safe (113). Low hospital volume has been demonstrated to be an important factor related to increased postoperative morbidity and mortality $(9,12,28,29,114)$, raising the issue of the number of LPD needed at each center to reach a relatively safe level. A recent study has shown that in pancreatic centers that have performed 10 or more LPD, the 30-day mortality rate after a laparoscopic procedure was equal to that of the open procedure $(0.0 \%$ vs. $0.7 \%, \mathrm{P}=1.00)(29)$. In addition, another study revealed that the benefits of LPD were hardly observed unless 25 or more PD could be implemented per year (28).

\section{Topic 13: LPD in elderly patients}

Statement: LPD can be safely performed in elderly patients without increasing the risk of postoperative morbidity and mortality.

Quality of evidence: Moderate.

Strength of recommendation: Strong.

Whether LPD can be performed safely in elderly patients as with conventional OPD is also a concern, although age increases the perioperative risk to elderly patients, LPD itself was not associated with increased morbidity and mortality (68). In fact, Tee et al. reported that in elderly patients, OPD has been shown to be associated with increased DGE (OR, 1.80, $\mathrm{P}=0.03)$, LOS (1 additional day, $\mathrm{P}<0.001)$ and rate of blood transfusion $(\mathrm{OR}, 2.89$, $\mathrm{P}<0.001)$, compared with LPD (68). In a study involving a large sample of 1,768 elderly ( $\geq 75$ years) patients, the 90-day mortality rate was lower in the LPD group than in the OPD group $(7.2 \%$ vs. $12.2 \%, \mathrm{P}=0.049)$. Of note, the median overall survival was also found to be longer in the LPD group (19.8 vs. 15.6 months, $\mathrm{P}=0.022)$ (115). Elderly patients undergoing LPD seem to experience higher overall morbidity than younger patients $(41 \%$ vs. $20 \%$, $\mathrm{P}=0.05$ ). However, in elderly patients who need to undergo pancreaticoduodenectomy, the mortality and morbidity rates were comparable between these two approaches, and LPD might have certain advantages over OPD (116). Similarly, several studies have also shown that LPD is safe and feasible in elderly patients $(43,117,118)$.

\section{Topic 14: Follow-up after LPD}

Statement: Recurrence-free and overall survival after LPD are equal to that after OPD, and both procedures achieve equivalent rates of radical resection margins and number of harvested lymph nodes. Patients who undergo LPD experience a more favorable quality of life in the first 6 months after surgery.

Quality of evidence: Moderate.

Strength of recommendation: Strong.

Young et al. reported a case of port-site recurrence following LPD (119). Therefore, it is of great concern whether LPD may compromise survival compared with OPD. Song et al. retrospectively reviewed the data of 500 consecutive patients who underwent LPD at a single institution between January 2007 and December 2017 , finding that the 5 -year overall survival rates of pancreatic, distal common biliary duct, ampulla of Vater, and duodenal cancer were $37.4 \%, 63.2 \%$, 78\%, and $88.9 \%$, respectively, and the median overall and recurrence-free survival following LPD for pancreatic cancer was 32.4 and 14.9 months, respectively (47). Chen et al. found that patients who underwent LPD had similar 1-year (OR, 1.20; 95\% CI, 0.87-1.65; P=0.28), and 2-year survival (OR, 1.25; 95\% CI, 0.94-1.66; $\mathrm{P}=0.13)$ rates to those who underwent $\mathrm{OPD}$. In contrast, the 3-year (OR, 1.50; 95\% CI, 1.12-2.02, $\mathrm{P}=0.007)$, 4-year (OR, 1.73; 95\% CI, 1.02-2.93, P=0.04), and 5-year (OR, 2.11; 95\% CI, 1.35-3.31, P=0.001) survival rates were significantly higher in the LPD group (24). Stauffer et al. (22) retrospectively analyzed 251 patients that underwent PD for PDAC, finding that the 
estimated median survival was 20.3 months for OPD and 18.5 months for LPD. The overall survival rate at 1, 2, 3, 4, and 5 years was similar after OPD $(68 \%, 40 \%, 24 \%, 17 \%$, and $15 \%$, respectively) and LPD $(67 \%, 43 \%, 43 \%, 38 \%$, and $32 \%$, respectively). Kim et al. studied 149 patients with pancreatic neuroendocrine tumors who underwent PD. The 3-year overall and disease-free survival rates were $91.9 \%$ and $94.8 \%$ in the LPD group, and $93.6 \%$ and $86.7 \%$ in the OPD group $(\mathrm{P}=0.974$ and 0.225 , respectively) (120). A meta-analysis performed by Peng et al., which included 10 studies with 11,180 patients $(1,437$ undergoing LPD and 9,743 undergoing OPD), showed that while LPD was associated with longer disease-free survival than OPD (hazard ratio, 0.77; 95\% CI, 0.61-0.98; $\mathrm{P}=0.033$ ), there was no significant difference in overall survival (hazard ratio, 0.98; 95\% CI, 0.90-1.07; $\mathrm{P}=0.672$ ). In addition, patients who had undergone LPD had a significantly shorter interval between surgery and initiation of adjuvant chemotherapy (weighted mean difference -10.17 ; $95 \% \mathrm{CI},-17.90$ to $-2.45 ; \mathrm{P}=0.010)$ (23), implying that patients would benefit from receiving chemotherapy earlier. Delitto et al. found that overall survival was not statistically different between patients undergoing LPD and OPD for periampullary adenocarcinoma (median overall survival 27.9 vs. 23.5 months; $\mathrm{P}=0.955$ ) or pancreatic adenocarcinoma (median overall survival 20.7 vs. 21.1 months; $\mathrm{P}=0.703$ ) (39). Deichmann et al. reported a matched pair analysis of 120 patients and discovered that patients that underwent LPD showed a trend towards improved median overall survival (56 vs. 48 months; $\mathrm{P}=0.056$ ) (103). A Chinese group has previously shown that the number of harvested lymph nodes, as well as 1-year recurrence-free and overall survival, was not significantly different between patients with malignant tumors that underwent LPD or OPD (121), which was consistence with results from other studies $(22,26,53,59,122)$. A further small cohort study by Conrad et al. reported 1-, 3-, and 5 -year overall survival rates for PDAC patients were $80.5 \%, 49.2 \%$, and $39.7 \%$, respectively, in the LPD group, compared to $77.8 \%, 46.4 \%$, and $30 \%$, in the OPD group $(\mathrm{P}=0.41,0.42$, and 0.25$)$. Similarly, the 1-, 3-, and 5-year recurrence-free survival rates for PDAC patients were $70.9 \%, 33.3 \%$, and $21.9 \%$, respectively, in LPD group, and $62.3 \%, 37.9 \%$, and $25.7 \%$ in OPD group $(\mathrm{P}=0.27$, 0.37 , and 0.39$)$, indicating that LPD achieves non-inferior survival outcomes (123). Similar findings were reported in another large study, where median overall survival for PDAC patients was 20.7 months in the LPD group and
20.9 months in the OPD group $(\mathrm{P}=0.68)$ (79). Moreover, a recent meta-analysis of 14,017 patients with pancreatic cancer demonstrated that overall survival after LPD was comparable to that after OPD (hazard ratio, $0.98 ; 95 \%$ CI, 0.90-1.07; $\mathrm{P}=0.672$ ). Importantly, recurrence-free survival was superior in patients that underwent LPD (hazard ratio, 0.77; 95\% CI, 0.61-0.98; $\mathrm{P}=0.033$ ) (23).

\section{Section 5: Surgical training and management of the learning curve}

\section{Topic 15: Surgical training}

Statement: While LPD is a safe and feasible procedure, it is technically challenging. Surgeons are encouraged to pursue training by means of detailed explanations of operative technique, video training, box trainers, virtual reality simulators, and proctored practice on porcine models. Training to improve surgeons ability to manage psychological stress should not be ignored as it would help surgeons perform better in challenging clinical situations. With the development of computer technology, increasingly more advanced digital processors and design features will help surgeons achieve better performance. LPD training programs should be established at large-volume pancreatic centers with a protocol in place to certify appropriately trained surgeons.

Quality of evidence: Moderate.

Strength of recommendation: Strong.

Although studies have shown it to be a safe and feasible treatment choice, LPD is indeed a complex and challenging procedure. Lack of experience with this approach was related to increased postoperative morbidity and mortality during the learning curve (124). Therefore, the technical training of young surgeons is critically important. As the starting point, trainees are encouraged to be familiar with traditional pancreaticoduodenectomy (55). Under the guidance and feedback of experienced pancreatic surgeons, video training, box trainers, and virtual reality simulators could be effective tools for surgical education and assessment (125-129). Despite the obvious anatomical differences, LPD was feasible in a porcine model $(40,130)$, giving another useful approach for surgical education. In addition, special psychological skills training is helpful for teaching surgical trainees to deal with unexpected events during surgery (131-134). Surgical instruments that involve more advanced digital processors and design features, such as grips that enhance tactile feedback, help trainees achieve better performance $(135,136)$. Moreover, de Rooij et al. recently reported the application of an LPD training 
program, including detailed explanation of operative technique, video training, and proctoring, to 8 surgeons from 4 high-volume centers. The program led to the achievement of acceptable rates of grade B/C POPF (34\%), Clavien-Dindo grade $\geq$ III complications $(43 \%)$, and 90 -day mortality (3.5\%), in all centers (55).

\section{Topic 16: Management of the learning curve}

Statement: Surgeons achieve technical competency after performing 30 to $50 \mathrm{LPD}$ procedures. Operation time, intraoperative blood loss, conversion, postoperative complication rate, and LOS are the indicators to be used for learning curve assessment.

Quality of evidence: Moderate.

Strength of recommendation: Strong.

The rate of postoperative complications after LPD is intimately associated with the learning curve $(12,124)$. Data from a previous cohort study showed that surgeons reached a learning curve plateau, in terms of operation time and blood loss, after performing 10 LPD (137). However, regardless of surgical complications and mortality, a 10-case learning curve is not entirely convincing. Indeed, another cohort study reported a significant reduction in operation time within the first 10 cases (61). In fact, operative time and blood loss only plateaued at 50 cases (61). In another retrospective cohort study, clinical outcomes improved after 30 to 60 LPD had been completed, as evidenced by a reduction of blood loss, decreased rate of postoperative morbidity, and shortened LOS (111).

Moreover, based on a cumulative sum analysis, a previous study has demonstrated that the learning curve for LPD involves three phases: initial learning (cases 1-11), technical competence (cases 12-38), and challenging cases (cases 39-57). Progression through the learning is evidenced by decreased operation time, blood loss, and postoperative ICU stay. Therefore, a minimum of 40 cases was recommended for attaining technical competence in LPD (112). Similarly, cumulative sum analysis in another study identified three learning phases to LPD. However, in that study, a minimum of 30 cases of LPD was suggested to achieve technical competence (34). According to Wang's recent large, multicenter study, LPD is associated with a three-phase learning curve, with proficiency thresholds at 40 and 104 cases (12).

\section{Conclusions}

During the past decades, there have been major advances in LPD. The use of such technique has been slowly gaining momentum, to the stage now with significant acceptance by pancreatic surgeons. Barriers, for instance, lack of training, video equipment, proper surgical instrumentation, or surgical skill, have gradually been overcome. Although operative time is generally longer when performing LPD, safety and feasibility are guaranteed in the hands of experienced pancreatic surgeons, compared with that of OPD. Importantly, the short- and long-term outcomes in patients who undergo LPD is equivalent to those who undergo OPD. Resource utilization and costs of LPD have been deemed to be potential drawback of such technique. However, although LPD had higher intraoperative costs, taken into account the decreased use of postoperative hospital resources and increased postoperative quality of life, overall costs could be identical between LPD and OPD.

\section{Acknowledgments}

Special thank goes to the consensus secretary (Junfang Zhao, Hang Zhang and Min Wang) for their vast and invaluable work on this project.

Funding: This study was supported by grants from The National Natural Science Foundation of China (81772950) and Tongji Hospital Clinical Research Flagship Program (2019CR203) to RQ.

\section{Footnote}

Reporting Checklist: The authors have completed the PRISMA reporting checklist. Available at http://dx.doi. org/10.21037/hbsn-20-446

Conflicts of Interest: All authors have completed the ICMJE uniform disclosure form (available at http://dx.doi. org/10.21037/hbsn-20-446). The authors have no conflicts of interest to declare.

Ethical Statement: The authors are accountable for all aspects of the work in ensuring that questions related to the accuracy or integrity of any part of the work are appropriately investigated and resolved.

Open Access Statement: This is an Open Access article distributed in accordance with the Creative Commons Attribution-NonCommercial-NoDerivs 4.0 International License (CC BY-NC-ND 4.0), which permits the non- 
commercial replication and distribution of the article with the strict proviso that no changes or edits are made and the original work is properly cited (including links to both the formal publication through the relevant DOI and the license). See: https://creativecommons.org/licenses/by-nc-nd/4.0/.

\section{References}

1. Gagner M, Pomp A. Laparoscopic pylorus-preserving pancreatoduodenectomy. Surg Endosc 1994;8:408-10.

2. Dokmak S, Aussilhou B, Calmels M, et al. Laparoscopic pancreaticoduodenectomy with reconstruction of the mesentericoportal vein with the parietal peritoneum and the falciform ligament. Surg Endosc 2018;32:3256-61.

3. Caruso F, Alessandri G, Cesana G, et al. Laparoscopic pancreaticoduodenectomy for tumors of the head of pancreas; 10 cases for a single center experience. Eur Rev Med Pharmacol Sci 2017;21:3745-53.

4. Gumbs AA, Gres P, Madureira FA, et al. Laparoscopic vs. open resection of noninvasive intraductal pancreatic mucinous neoplasms. J Gastrointest Surg 2008;12:707-12.

5. Bausch D, Keck T. Laparoscopic pancreatic resections. Langenbecks Arch Surg 2013;398:939-45.

6. Nickel F, Haney CM, Kowalewski KF, et al. Laparoscopic versus open pancreaticoduodenectomy: a systematic review and meta-analysis of randomized controlled trials. Ann Surg 2020;271:54-66.

7. Klompmaker S, van Hilst J, Wellner UF, et al. Outcomes after minimally-invasive versus open pancreatoduodenectomy: a Pan-European Propensity Score Matched Study. Ann Surg 2020;271:356-63.

8. Poves I, Burdio F, Morato O, et al. Comparison of perioperative outcomes between laparoscopic and open approach for pancreatoduodenectomy: the PADULAP randomized controlled trial. Ann Surg 2018;268:731-9.

9. Torphy RJ, Friedman C, Halpern A, et al. Comparing short-term and oncologic outcomes of minimally invasive versus open pancreaticoduodenectomy across low and high volume centers. Ann Surg 2019;270:1147-55.

10. de Rooij T, Lu MZ, Steen MW, et al. Minimally invasive versus open pancreatoduodenectomy: systematic review and meta-analysis of comparative cohort and registry studies. Ann Surg 2016;264:257-67.

11. van Hilst J, de Rooij T, Bosscha K, et al. Laparoscopic versus open pancreatoduodenectomy for pancreatic or periampullary tumours (LEOPARD-2): a multicentre, patient-blinded, randomised controlled phase $2 / 3$ trial. Lancet Gastroenterol Hepatol 2019;4:199-207.
12. Wang M, Peng B, Liu J, et al. Practice patterns and perioperative outcomes of laparoscopic pancreaticoduodenectomy in China: a retrospective multicenter analysis of 1029 patients. Ann Surg 2019. [Epub ahead of print].

13. Ausania F, Landi F, Martinez-Perez A, et al. A metaanalysis of randomized controlled trials comparing laparoscopic vs open pancreaticoduodenectomy. HPB (Oxford) 2019;21:1613-20.

14. Palanivelu C, Senthilnathan P, Sabnis SC, et al. Randomized clinical trial of laparoscopic versus open pancreatoduodenectomy for periampullary tumours. Br J Surg 2017;104:1443-50.

15. Liu R, Wakabayashi G, Palanivelu C, et al. International consensus statement on robotic pancreatic surgery. Hepatobiliary Surg Nutr 2019;8:345-60.

16. Zhao W, Liu C, Li S, et al. Safety and efficacy for robotassisted versus open pancreaticoduodenectomy and distal pancreatectomy: a systematic review and meta-analysis. Surg Oncol 2018;27:468-78.

17. Zhang Y, Hong D, Zhang C, et al. Total laparoscopic versus robot-assisted laparoscopic pancreaticoduodenectomy. Biosci Trends 2018;12:484-90.

18. Edwin B, Sahakyan MA, Abu Hilal M, et al. Laparoscopic surgery for pancreatic neoplasms: the European association for endoscopic surgery clinical consensus conference. Surg Endosc 2017;31:2023-41.

19. AGREE Collaboration. Development and validation of an international appraisal instrument for assessing the quality of clinical practice guidelines: the AGREE project. Qual Saf Health Care 2003;12:18-23.

20. Cuschieri A. Laparoscopic pancreatic resections. Semin Laparosc Surg 1996;3:15-20.

21. Dokmak S, Fteriche FS, Aussilhou B, et al. Laparoscopic pancreaticoduodenectomy should not be routine for resection of periampullary tumors. J Am Coll Surg 2015;220:831-8.

22. Stauffer JA, Coppola A, Villacreses D, et al. Laparoscopic versus open pancreaticoduodenectomy for pancreatic adenocarcinoma: long-term results at a single institution. Surg Endosc 2017;31:2233-41.

23. Peng L, Zhou Z, Cao Z, et al. Long-term oncological outcomes in laparoscopic versus open pancreaticoduodenectomy for pancreatic cancer: a systematic review and meta-analysis. J Laparoendosc Adv Surg Tech A 2019;29:759-69.

24. Chen K, Zhou Y, Jin W, et al. Laparoscopic pancreaticoduodenectomy versus open 
pancreaticoduodenectomy for pancreatic ductal adenocarcinoma: oncologic outcomes and long-term survival. Surg Endosc 2020;34:1948-58.

25. Meng LW, Cai YQ, Li YB, et al. Comparison of laparoscopic and open pancreaticoduodenectomy for the treatment of nonpancreatic periampullary adenocarcinomas. Surg Laparosc Endosc Percutan Tech 2018;28:56-61.

26. Zureikat AH, Breaux JA, Steel JL, et al. Can laparoscopic pancreaticoduodenectomy be safely implemented? J Gastrointest Surg 2011;15:1151-7.

27. Qin H, Qiu J, Zhao Y, et al. Does minimally-invasive pancreaticoduodenectomy have advantages over its open method? A meta-analysis of retrospective studies. PLoS One 2014;9:e104274.

28. Kutlu OC, Lee JE, Katz MH, et al. Open pancreaticoduodenectomy case volume predicts outcome of laparoscopic approach: a population-based analysis. Ann Surg 2018;267:552-60.

29. Sharpe SM, Talamonti MS, Wang CE, et al. Early national experience with laparoscopic pancreaticoduodenectomy for ductal adenocarcinoma: a comparison of laparoscopic pancreaticoduodenectomy and open pancreaticoduodenectomy from the National Cancer Data Base. J Am Coll Surg 2015;221:175-84.

30. Kendrick ML, van Hilst J, Boggi U, et al. Minimally invasive pancreatoduodenectomy. HPB (Oxford) 2017;19:215-24.

31. Senthilnathan P, Srivatsan Gurumurthy S, Gul SI, et al. Long-term results of laparoscopic pancreaticoduodenectomy for pancreatic and periampullary cancer-experience of 130 cases from a tertiary-care center in South India. J Laparoendosc Adv Surg Tech A 2015;25:295-300.

32. Low TY, Goh BKP. Initial experience with minimally invasive extended pancreatectomies for locally advanced pancreatic malignancies: report of six cases. J Minim Access Surg 2019;15:204-9.

33. Goh BKP, Low TY, Kam JH, et al. Initial experience with laparoscopic and robotic surgery for the treatment of periampullary tumours: single institution experience with the first 30 consecutive cases. ANZ J Surg 2019;89:E137-41.

34. Nagakawa Y, Nakamura Y, Honda G, et al. Learning curve and surgical factors influencing the surgical outcomes during the initial experience with laparoscopic pancreaticoduodenectomy. J Hepatobiliary Pancreat Sci 2018;25:498-507.
35. Coelho JCU, da Costa MAR, Ramos EJB, et al. Surgical management of solid pseudopapillary tumor of the pancreas. JSLS 2018;22:e2018.00032.</unknown>

36. Kendrick ML, Sclabas GM. Major venous resection during total laparoscopic pancreaticoduodenectomy. HPB (Oxford) 2011;13:454-8.

37. Finnesgard EJ, Pandian TK, Kendrick ML, et al. Do not break up the surgical team! Familiarity and expertise affect operative time in complex surgery. Am J Surg 2018;215:447-9.

38. Maruthappu M, Duclos A, Zhou CD, et al. The impact of team familiarity and surgical experience on operative efficiency: a retrospective analysis. J R Soc Med 2016;109:147-53.

39. Delitto D, Luckhurst CM, Black BS, et al. Oncologic and perioperative outcomes following selective application of laparoscopic pancreaticoduodenectomy for periampullary malignancies. J Gastrointest Surg 2016;20:1343-9.

40. Cho A, Yamamoto H, Nagata M, et al. Comparison of laparoscopy-assisted and open pylorus-preserving pancreaticoduodenectomy for periampullary disease. Am J Surg 2009;198:445-9.

41. Kumar H, Morad R, Sonsati M. Surgical team: improving teamwork, a review. Postgrad Med J 2019;95:334-9.

42. Cai Y, Chen S, Peng B. Two-surgeon model in laparoscopic pancreaticoduodenectomy. Surg Laparosc Endosc Percutan Tech 2019;29:275-9.

43. Zhou J, Xin C, Xia T, et al. Laparoscopic pancreaticoduodenectomy in A-92-older Chinese patient for cancer of head of the pancreas: a case report. Medicine (Baltimore) 2017;96:e5962.

44. Yin Z, Jian Z, Hou B, et al. Surgical and oncological outcomes of laparoscopic versus open pancreaticoduodenectomy in patients with pancreatic duct adenocarcinoma. Pancreas 2019;48:861-7.

45. Ialongo P, Milella M, Pascazio B, et al. Laparoscopic management of pancreatic cancer. Our experience. Ann Ital Chir 2015;86:518-23.

46. Tan JKH, Ng JJ, Yeo M, et al. Propensity score-matched analysis of early outcomes after laparoscopic-assisted versus open pancreaticoduodenectomy. ANZ J Surg 2019;89:E190-4.

47. Song KB, Kim SC, Lee W, et al. Laparoscopic pancreaticoduodenectomy for periampullary tumors: lessons learned from 500 consecutive patients in a single center. Surg Endosc 2020;34:1343-52.

48. Wang X, Cai Y, Zhao W, et al. Laparoscopic pancreatoduodenectomy combined with portal-superior 
mesenteric vein resection and reconstruction with interposition graft: Case series. Medicine (Baltimore) 2019;98:e14204.

49. Wang M, Zhu F, Qin R, et al. Which is the best surgical approach for the pancreatic cancer? A classification of pancreatic cancer to guide operative decisions is needed. Ann Surg 2017;265:E81-2.

50. Liu M, Ji S, Xu W, et al. Laparoscopic pancreaticoduodenectomy: are the best times coming? World J Surg Oncol 2019;17:81.

51. Khaled YS, Fatania K, Barrie J, et al. Matched casecontrol comparative study of laparoscopic versus open pancreaticoduodenectomy for malignant lesions. Surg Laparosc Endosc Percutan Tech 2018;28:47-51.

52. Wang XM, Sun WD, Hu MH, et al. Inferoposterior duodenal approach for laparoscopic pancreaticoduodenectomy. World J Gastroenterol 2016;22:2142-8

53. Wang $M$, Zhang $\mathrm{H}, \mathrm{Wu} Z$, et al. Laparoscopic pancreaticoduodenectomy: single-surgeon experience. Surg Endosc 2015;29:3783-94.

54. Cesaretti M, Bifulco L, Costi R, et al. Pancreatic resection in the era of laparoscopy: State of Art. A systematic review. Int J Surg 2017;44:309-16.

55. de Rooij T, van Hilst J, Topal B, et al. Outcomes of a multicenter training program in laparoscopic pancreatoduodenectomy (LAELAPS-2). Ann Surg 2019;269:344-50.

56. Palanivelu C, Rajan PS, Rangarajan M, et al. Evolution in techniques of laparoscopic pancreaticoduodenectomy: a decade long experience from a tertiary center. J Hepatobiliary Pancreat Surg 2009;16:731-40.

57. Corcione F, Pirozzi F, Cuccurullo D, et al. Laparoscopic pancreaticoduodenectomy: experience of 22 cases. Surg Endosc 2013;27:2131-6.

58. Dulucq JL, Wintringer P, Mahajna A. Laparoscopic pancreaticoduodenectomy for benign and malignant diseases. Surg Endosc 2006;20:1045-50.

59. Kuesters S, Chikhladze S, Makowiec F, et al. Oncological outcome of laparoscopically assisted pancreatoduodenectomy for ductal adenocarcinoma in a retrospective cohort study. Int J Surg 2018;5 5:162-6.

60. Mehrabi A, Hafezi M, Arvin J, et al. A systematic review and meta-analysis of laparoscopic versus open distal pancreatectomy for benign and malignant lesions of the pancreas: it's time to randomize. Surgery 2015;157:45-55.

61. Speicher PJ, Nussbaum DP, White RR, et al. Defining the learning curve for team-based laparoscopic pancreaticoduodenectomy. Ann Surg Oncol 2014;21:4014-9.

62. Palanivelu C, Jani K, Senthilnathan P, et al. Laparoscopic pancreaticoduodenectomy: technique and outcomes. J Am Coll Surg 2007;205:222-30.

63. Langan RC, Graham JA, Chin AB, et al. Laparoscopicassisted versus open pancreaticoduodenectomy: early favorable physical quality-of-life measures. Surgery 2014;156:379-84.

64. Lee JS, Han JH, Na GH, et al. Laparoscopic pancreaticoduodenectomy assisted by mini-laparotomy. Surg Laparosc Endosc Percutan Tech 2013;23:e98-102.

65. de Rooij T, Klompmaker S, Abu Hilal M, et al. Laparoscopic pancreatic surgery for benign and malignant disease. Nat Rev Gastroenterol Hepatol 2016;13:227-38.

66. Cai Y, Gao P, Li Y, et al. Laparoscopic pancreaticoduodenectomy with major venous resection and reconstruction: anterior superior mesenteric artery first approach. Surg Endosc 2018;32:4209-15.

67. Chopinet S, Fuks D, Rinaudo M, et al. Postoperative Bleeding After Laparoscopic Pancreaticoduodenectomy: the Achilles' Heel? World J Surg 2018;42:1138-46.

68. Tee MC, Croome KP, Shubert CR, et al. Laparoscopic pancreatoduodenectomy does not completely mitigate increased perioperative risks in elderly patients. HPB (Oxford) 2015;17:909-18.

69. Jeune F, Coriat R, Prat F, et al. Pancreatic cancer surgical management. Presse Med 2019;48:e147-58.

70. Broucek JR, Sanford D, Stauffer JA, et al. Minimally invasive approaches to pancreatic cancer. Surg Oncol Clin N Am 2019;28:255-72.

71. Liao CH, Liu YY, Wang SY, et al. The feasibility of laparoscopic pancreaticoduodenectomy-a stepwise procedure and learning curve. Langenbecks Arch Surg 2017;402:853-61.

72. Guerra F, Checcacci P, Vegni A, et al. Surgical and oncological outcomes of our first 59 cases of robotic pancreaticoduodenectomy. J Visc Surg 2019;156:185-90.

73. Giulianotti PC, Mangano A, Bustos RE, et al. Operative technique in robotic pancreaticoduodenectomy (RPD) at University of Illinois at Chicago (UIC): 17 steps standardized technique: lessons learned since the first worldwide RPD performed in the year 2001. Surg Endosc 2018;32:4329-36.

74. Correa-Gallego C, Dinkelspiel HE, Sulimanoff I, et al. Minimally-invasive vs open pancreaticoduodenectomy: systematic review and meta-analysis. J Am Coll Surg 2014;218:129-39. 
75. Croome KP, Farnell MB, Que FG, et al. Total laparoscopic pancreaticoduodenectomy for pancreatic ductal adenocarcinoma: oncologic advantages over open approaches? Ann Surg 2014;260:633-8; discussion 638-40.

76. Palanisamy S, Deuri B, Naidu SB, et al. Major venous resection and reconstruction using a minimally invasive approach during laparoscopic pancreaticoduodenectomy: one step forward. Asian J Endosc Surg 2015;8:468-72.

77. Song KB, Kim SC, Hwang DW, et al. Matched casecontrol analysis comparing laparoscopic and open pyloruspreserving pancreaticoduodenectomy in patients with periampullary tumors. Ann Surg 2015;262:146-55.

78. Hakeem AR, Verbeke CS, Cairns A, et al. A matched-pair analysis of laparoscopic versus open pancreaticoduodenectomy: oncological outcomes using Leeds Pathology Protocol. Hepatobiliary Pancreat Dis Int 2014;13:435-41.

79. Kantor O, Talamonti MS, Sharpe S, et al. Laparoscopic pancreaticoduodenectomy for adenocarcinoma provides short-term oncologic outcomes and longterm overall survival rates similar to those for open pancreaticoduodenectomy. Am J Surg 2017;213:512-5.

80. Asbun HJ, Stauffer JA. Laparoscopic vs open pancreaticoduodenectomy: overall outcomes and severity of complications using the Accordion Severity Grading System. J Am Coll Surg 2012;215:810-9.

81. Tan CL, Zhang H, Peng B, et al. Outcome and costs of laparoscopic pancreaticoduodenectomy during the initial learning curve vs laparotomy. World J Gastroenterol 2015;21:5311-9.

82. Chen K, Liu XL, Pan Y, et al. Expanding laparoscopic pancreaticoduodenectomy to pancreatic-head and periampullary malignancy: major findings based on systematic review and meta-analysis. BMC Gastroenterol 2018;18:102.

83. Poves I, Morato O, Burdio F, et al. Laparoscopicadapted Blumgart pancreaticojejunostomy in laparoscopic pancreaticoduodenectomy. Surg Endosc 2017;31:2837-45.

84. Vera R, Diez L, Martin Perez E, et al. Surgery for pancreatic ductal adenocarcinoma. Clin Transl Oncol 2017;19:1303-11.

85. Kim EY, Hong TH. Total laparoscopic pancreaticoduodenectomy using a new technique of pancreaticojejunostomy with two transpancreatic sutures with buttresses. J Laparoendosc Adv Surg Tech A 2016;26:133-9.

86. Cho A, Yamamoto H, Kainuma O, et al. Performing simple and safe dunking pancreaticojejunostomy using mattress sutures in pure laparoscopic pancreaticoduodenectomy. Surg Endosc 2014;28:315-8.

87. Lu B, Huang Y, Cai X, et al. A novel method for reconstruction in laparoscopic pancreaticoduodenectomy: an experience of 13 cases. Front Med China 2007;1:369-72.

88. Lei Z, Zhifei W, Jun X, et al. Pancreaticojejunostomy sleeve reconstruction after pancreaticoduodenectomy in laparoscopic and open surgery. JSLS 2013;17:68-73.

89. Hughes SJ, Neichoy B, Behrns KE. Laparoscopic intussuscepting pancreaticojejunostomy. J Gastrointest Surg 2014;18:208-12.

90. Cai Y, Luo H, Li Y, et al. A novel technique of pancreaticojejunostomy for laparoscopic pancreaticoduodenectomy. Surg Endosc 2019;33:1572-7.

91. Kleespies A, Rentsch M, Seeliger H, et al. Blumgart anastomosis for pancreaticojejunostomy minimizes severe complications after pancreatic head resection. Br J Surg 2009;96:741-50.

92. Puntambekar SP, Mehta MJ, Manchekar MM, et al. Laparoscopic intracorporeal pancreaticogastrostomy in total laparoscopic pancreaticoduodenectomy-a novel anastomotic technique. Indian J Surg Oncol 2019;10:274-9.

93. Matsuda M, Haruta S, Shinohara $\mathrm{H}$, et al. Pancreaticogastrostomy in pure laparoscopic pancreaticoduodenectomy--A novel pancreatic-gastric anastomosis technique. BMC Surg 2015;15:80.

94. Wang M, Xu S, Zhang H, et al. Imbedding pancreaticojejunostomy used in pure laparoscopic pancreaticoduodenectomy for nondilated pancreatic duct. Surg Endosc 2017;31:1986-92.

95. Nakamura Y, Matsumoto S, Matsushita A, et al. Pancreaticojejunostomy with closure of the pancreatic stump by endoscopic linear stapler in laparoscopic pancreaticoduodenectomy: a reliable technique and benefits for pancreatic resection. Asian J Endosc Surg 2012;5:191-4.

96. Hong DF, Liu YH, Zhang YH, et al. The role of Hong's single-stitch duct to mucosa pancreaticojejunostomy in laparoscopic pancreaticoduodenectomy. Zhonghua Wai Ke Za Zhi 2017;55:136-40.

97. Wang S, Shi N, You L, et al. Minimally invasive surgical approach versus open procedure for pancreaticoduodenectomy: a systematic review and metaanalysis. Medicine (Baltimore) 2017;96:e8619.

98. Liang S, Jayaraman S. Getting started with minimally invasive pancreaticoduodenectomy: is it worth it? J 
Laparoendosc Adv Surg Tech A 2015;25:712-9.

99. Jiang CY, Liang Y, Wang HW, et al. Management of the uncinate process via the artery first approach in laparoscopic pancreatoduodenectomy. J Hepatobiliary Pancreat Sci 2019;26:410-5.

100. McCracken EKE, Mureebe L, Blazer DG 3rd. Minimally invasive surgical site infection in procedure-targeted ACS NSQIP pancreaticoduodenectomies. J Surg Res 2019;233:183-91.

101. Chapman BC, Gleisner A, Ibrahim-Zada I, et al. Laparoscopic pancreaticoduodenectomy: changing the management of ampullary neoplasms. Surg Endosc 2018;32:915-22.

102. Chen K, Pan Y, Liu XL, et al. Minimally invasive pancreaticoduodenectomy for periampullary disease: a comprehensive review of literature and meta-analysis of outcomes compared with open surgery. BMC Gastroenterol 2017;17:120.

103. Deichmann S, Bolm LR, Honselmann KC, et al. Perioperative and long-term oncological results of minimally invasive pancreatoduodenectomy as hybrid technique - a matched pair analysis of 120 cases. Zentralbl Chir 2018;143:155-61.

104. Pang L, Kong J, Wang Y, et al. Laparoscopic versus open pylorus-preserving pancreatoduodenectomy. The first meta-analyse of retrospective matched cases. Acta Cir Bras 2018;33:40-8.

105. Moghadamyeghaneh Z, Sleeman D, Stewart L. Minimalinvasive approach to pancreatoduodenectomy is associated with lower early postoperative morbidity. Am J Surg 2019;217:718-24.

106.Zhang H, Guo X, Xia J, et al. Comparison of totally 3-dimensional laparoscopic pancreaticoduodenectomy and open pancreaticoduodenectomy. Pancreas 2018;47:592-600.

107.Nakamura M, Nakashima H. Laparoscopic distal pancreatectomy and pancreatoduodenectomy: is it worthwhile? A meta-analysis of laparoscopic pancreatectomy. J Hepatobiliary Pancreat Sci 2013;20:421-8.

108. Chopinet S, Fuks D, Gregoire E, et al. Authors' reply: postoperative bleeding after laparoscopic pancreaticoduodenectomy: the achilles' heel? World J Surg 2018;42:3060-1.

109. Wang H, Wang Y, Xing H, et al. Laparoscopic surgery within an enhanced recovery after surgery (ERAS) protocol reduced postoperative ileus by increasing postoperative treg levels in patients with right-side colon carcinoma.
Med Sci Monit 2018;24:7231-7.

110.Ni X, Jia D, Guo Y, et al. The efficacy and safety of enhanced recovery after surgery (ERAS) program in laparoscopic digestive system surgery: a meta-analysis of randomized controlled trials. Int J Surg 2019;69:108-15.

111.Lu C, Jin W, Mou YP, et al. Analysis of learning curve for laparoscopic pancreaticoduodenectomy. J Vis Surg 2016;2:145.

112. Wang M, Meng L, Cai Y, et al. Learning curve for laparoscopic pancreaticoduodenectomy: a CUSUM analysis. J Gastrointest Surg 2016;20:924-35.

113.Lu B, Cai X, Lu W, et al. Laparoscopic pancreaticoduodenectomy to treat cancer of the ampulla of Vater. JSLS 2006;10:97-100.

114.Adam MA, Choudhury K, Dinan MA, et al. Minimally invasive versus open pancreaticoduodenectomy for cancer: practice patterns and short-term outcomes among 7061 patients. Ann Surg 2015;262:372-7.

115. Chapman BC, Gajdos C, Hosokawa P, et al. Comparison of laparoscopic to open pancreaticoduodenectomy in elderly patients with pancreatic adenocarcinoma. Surg Endosc 2018;32:2239-48.

116.Liang Y, Zhao L, Jiang C, et al. Laparoscopic pancreaticoduodenectomy in elderly patients. Surg Endosc 2020;34:2028-34.

117.Sunagawa H, Mayama Y, Orokawa T, et al. Laparoscopic total remnant pancreatectomy after laparoscopic pancreaticoduodenectomy. Asian J Endosc Surg 2014;7:71-4.

118. Meng L, Xia Q, Cai Y, et al. Impact of patient age on morbidity and survival following laparoscopic pancreaticoduodenectomy. Surg Laparosc Endosc Percutan Tech 2019;29:378-82.

119. Young S, Abbitt P, Hughes SJ. Port-site recurrence of pancreatic adenocarcinoma following laparoscopic pancreaticoduodenectomy. J Gastrointest Surg 2012;16:2294-6.

120. Kim H, Song KB, Hwang DW, et al. Laparoscopic versus open pancreaticoduodenectomy for pancreatic neuroendocrine tumors: a single-center experience. Surg Endosc 2019;33:4177-85.

121. Wei H, Wei B, Zheng Z, et al. Comparative study of outcomes after laparoscopic versus open pancreaticoduodenectomy. Zhonghua Wei Chang Wai Ke Za Zhi 2014;17:465-8.

122. Paniccia A, Schulick RD, Edil BH. Total laparoscopic pancreaticoduodenectomy: a single-institutional experience. Ann Surg Oncol 2015;22:4380-1. 
123. Conrad C, Basso V, Passot G, et al. Comparable longterm oncologic outcomes of laparoscopic versus open pancreaticoduodenectomy for adenocarcinoma: a propensity score weighting analysis. Surg Endosc 2017;31:3970-8.

124. Kim SC, Song KB, Jung YS, et al. Short-term clinical outcomes for 100 consecutive cases of laparoscopic pylorus-preserving pancreatoduodenectomy: improvement with surgical experience. Surg Endosc 2013;27:95-103.

125.Kuroki T, Fujioka H. Training for laparoscopic pancreaticoduodenectomy. Surg Today 2019;49:103-7.

126. Yiannakopoulou E, Nikiteas N, Perrea D, et al. Virtual reality simulators and training in laparoscopic surgery. Int J Surg 2015;13:60-4.

127. Schmidt MW, Kowalewski KF, Schmidt ML, et al. The Heidelberg VR Score: development and validation of a composite score for laparoscopic virtual reality training. Surg Endosc 2019;33:2093-103.

128. Larsen CR, Soerensen JL, Grantcharov TP, et al. Effect of virtual reality training on laparoscopic surgery: randomised controlled trial. BMJ 2009;338:b1802.

129. Brinkmann C, Fritz M, Pankratius U, et al. Box- or virtual-reality trainer: which tool results in better transfer of laparoscopic basic skills?-a prospective randomized trial. J Surg Educ 2017;74:724-35.

130.Jones DB, Wu JS, Soper NJ. Laparoscopic pancreaticoduodenectomy in the porcine model. Surg Endosc 1997;11:326-30.

Cite this article as: Qin R, Kendrick ML, Wolfgang CL, Edil BH, Palanivelu C, Parks RW, Yang Y, He J, Zhang T, Mou Y, Yu X, Peng B, Senthilnathan P, Han HS, Lee JH, Unno M, Olde Damink SWM, Bansal VK, Chow P, Cheung TT, Choi N, Tien YW, Wang C, Fok M, Cai X, Zou S, Peng S, Zhao Y. International expert consensus on laparoscopic pancreaticoduodenectomy. HepatoBiliary Surg Nutr 2020;9(4):464-483. doi: 10.21037/hbsn-20-446
131. Anton NE, Mizota T, Whiteside JA, et al. Mental skills training limits the decay in operative technical skill under stressful conditions: results of a multisite, randomized controlled study. Surgery 2019;165:1059-64.

132. Anton NE, Mizota T, Timsina LR, et al. Attentional selectivity, automaticity, and self-efficacy predict simulatoracquired skill transfer to the clinical environment. Am J Surg 2019;217:266-71.

133. Anton NE, Beane J, Yurco AM, et al. Mental skills training effectively minimizes operative performance deterioration under stressful conditions: results of a randomized controlled study. Am J Surg 2018;215:214-21.

134.Huang JJ, Yeo CJ, Sohn TA, et al. Quality of life and outcomes after pancreaticoduodenectomy. Ann Surg 2000;231:890-8.

135. Alleblas CCJ, Vleugels MPH, Coppus S, et al. The effects of laparoscopic graspers with enhanced haptic feedback on applied forces: a randomized comparison with conventional graspers. Surg Endosc 2017;31:5411-7.

136. Araki A, Makiyama K, Yamanaka H, et al. Comparison of the performance of experienced and novice surgeons: measurement of gripping force during laparoscopic surgery performed on pigs using forceps with pressure sensors. Surg Endosc 2017;31:1999-2005.

137. Kuroki T, Kitasato A, Adachi T, et al. Learning curve for laparoscopic pancreaticoduodenectomy: a single surgeon's experience with consecutive patients. Hepatogastroenterology 2014;61:838-41. 
Supplementary

Table S1 Global distribution of participated experts

\begin{tabular}{ll}
\hline Country & Name \\
\hline China (Mainland) & $\begin{array}{l}\text { Renyi Qin, Yinmo Yang, Taiping Zhang, Yiping Mou, Xianjun Yu, Bing Peng, Chengfeng Wang, } \\
\text { Xiujun Cai, Shengquan Zou, Shuyou Peng, Yupei Zhao }\end{array}$ \\
China (Hongkong) & Tan To Cheung \\
China (Macau) & Nim Choi, Manson Fok \\
China (Taiwan) & Yu-Wen Tien \\
India & Chinnusamy Palanivelu, Palanisamy Senthilnathan, Virinder Kumar Bansal \\
Japan & Michiaki Unno \\
Korea & Ho-Seong Han, Jae Hoon Lee \\
Netherlands & Steven W. M. Olde Damink \\
Singapore & Pierce Chow \\
UK & Rowan Parks \\
USA & Michael Kendrick, Christopher Wolfgang, Barish Edil, Jin He \\
\hline
\end{tabular}


Table S2 Summary of recommendations

\begin{tabular}{|c|c|c|c|c|c|}
\hline Domain & $\mathrm{N}$ & Topic & Statement & $\begin{array}{l}\text { Quality of } \\
\text { evidence }\end{array}$ & $\begin{array}{l}\text { Grade } \\
\text { recommendation }\end{array}$ \\
\hline \multirow[t]{4}{*}{ Implementation } & 1 & $\begin{array}{l}\text { Safety and } \\
\text { feasibility }\end{array}$ & $\begin{array}{l}\text { LPD is safe and feasible compared with OPD, when performed in large volume medical centers by experienced surgeons. LPD is associated with a longer operative } \\
\text { time, less intraoperative blood loss, and shorter LOS than OPD, while its overall complication and perioperative mortality rates are equivalent }\end{array}$ & Moderate & Strong \\
\hline & 2 & $\begin{array}{l}\text { Volume of } \\
\text { pancreatic center } \\
\text { and LPD }\end{array}$ & $\begin{array}{l}\text { LPD should be carried out in pancreatic center with at least } 25 \text { cases of OPD per year. In addition, a robust radiology department and experienced interventionalists, } \\
\text { as well as the pathology and anesthesiology departments, should also work closely together in order to carry out the surgery successfully }\end{array}$ & Moderate & Strong \\
\hline & 3 & $\begin{array}{l}\text { Surgeon's } \\
\text { experience and } \\
\text { LPD }\end{array}$ & $\begin{array}{l}\text { In order to perform LPD successfully, surgeons should meet the following criteria: (I) surgeons should have advanced laparoscopic skills. Advancement through the } \\
\text { learning curve of minimally invasive surgery from basic to complex procedures, and mastering basic laparoscopic skills, such as dissection, suturing, and knotting, } \\
\text { is essential before starting to perform LPD. (II) Experienced in OPD. Surgeons and teams intending to adopt LPD should first be proficient in OPD with each } \\
\text { individual having a cumulative experience of }>50 \text { cases }\end{array}$ & Moderate & Strong \\
\hline & 4 & $\begin{array}{l}\text { Surgical team and } \\
\text { LPD }\end{array}$ & The operating surgeon, assistant surgeon, anesthesiologist, and nursing team for LPD should be relatively fixed & Low & Weak \\
\hline \multirow{3}{*}{$\begin{array}{l}\text { Indications, } \\
\text { contraindications, } \\
\text { and preoperative } \\
\text { preparation }\end{array}$} & 5 & Indications & $\begin{array}{l}\text { Indications of LPD could be similar to those of OPD, and should be determined by a MDT discussion before surgery, with careful consideration of the stage of the } \\
\text { learning curve at which the surgeon is located }\end{array}$ & Moderate & Strong \\
\hline & 6 & Contraindications & Contraindications of LPD could be similar to those of OPD, in addition to some laparoscopic contraindications & Moderate & Weak \\
\hline & 7 & $\begin{array}{l}\text { Preoperative } \\
\text { preparation }\end{array}$ & $\begin{array}{l}\text { The preoperative preparation for LPD patients are consistent with those for OPD patients. Surgeons per se should also be prepared with proficient surgical skills for } \\
\text { reducing the rate of conversion to laparotomy }\end{array}$ & Moderate & Strong \\
\hline \multirow[t]{2}{*}{ Technique } & 8 & Types of LPD & $\begin{array}{l}\text { There are four types of LPD: total, hand-assisted, laparoscopy-assisted, and robotic-assistance. Each is defined below. The choice of operative approach should be } \\
\text { made in accordance with the stage of learning cure at which the surgeon is located. Robotic surgery for LPD may offer several advantages, especially for digestive } \\
\text { tract reconstruction. However, due to its high cost, it is not widely utilized }\end{array}$ & Moderate & Strong \\
\hline & 9 & $\begin{array}{l}\text { The approach to } \\
\text { resection during } \\
\text { LPD }\end{array}$ & $\begin{array}{l}\text { The principles of tumor resection by LPD should be similar to those of standard OPD for different types of cancer. Short-term oncologic outcomes (harvested lymph } \\
\text { nodes/positive resection margins) are comparable between LPD and OPD }\end{array}$ & Moderate & Strong \\
\hline Technique & 10 & $\begin{array}{l}\text { Gastrointestinal } \\
\text { reconstruction } \\
\text { during LPD }\end{array}$ & $\begin{array}{l}\text { The reconstruction phase during LPD is especially technically demanding and time-consuming, taking longer than that during OPD. However, the morbidity } \\
\text { associated with gastrointestinal reconstruction is comparable between LPD and OPD }\end{array}$ & Moderate & Strong \\
\hline \multirow[t]{4}{*}{$\begin{array}{l}\text { Postoperative } \\
\text { management and } \\
\text { follow-up }\end{array}$} & 11 & $\begin{array}{l}\text { Postoperative } \\
\text { morbidity }\end{array}$ & $\begin{array}{l}\text { LPD, although complicated and technically demanding, is safe and effective in the hands of experienced surgeons. The rate of complications in patients who } \\
\text { undergo LPD is equivalent to those who undergo OPD. Moreover, patients benefit from the laparoscopic approach with respect to reduced blood loss and surgical } \\
\text { site infections, and a shortened hospital stay }\end{array}$ & High & Strong \\
\hline & 12 & $\begin{array}{l}\text { Postoperative } \\
\text { mortality }\end{array}$ & $\begin{array}{l}\text { The mortality rate after LPD is a significant safety concern. Therefore, LPD should only be performed by skilled laparoscopic surgeons with proper training in high- } \\
\text { volume pancreatic centers. Further large trials involving well-trained laparoscopic surgeons at high-volume hospitals are needed to clarify this concern }\end{array}$ & Moderate & Strong \\
\hline & 13 & $\begin{array}{l}\text { LPD in elderly } \\
\text { patients }\end{array}$ & LPD can be safely performed in elderly patients without increasing the risk of postoperative morbidity and mortality & Moderate & Strong \\
\hline & 14 & $\begin{array}{l}\text { Follow-up after } \\
\text { LPD }\end{array}$ & $\begin{array}{l}\text { Recurrence-free and overall survival after LPD are equal to that after OPD, and both procedures achieve equivalent rates of radical resection margins and number } \\
\text { of harvested lymph nodes. Patients who undergo LPD experience a more favorable quality of life in the first } 6 \text { months after surgery }\end{array}$ & Moderate & Strong \\
\hline \multirow[t]{2}{*}{$\begin{array}{l}\text { Surgical training and } \\
\text { management of the } \\
\text { learning curve }\end{array}$} & 15 & Surgical training & $\begin{array}{l}\text { While LPD is a safe and feasible procedure, it is technically challenging. Surgeons are encouraged to pursue training by means of detailed explanations of } \\
\text { operative technique, video training, box trainers, virtual reality simulators, and proctored practice on porcine models. Training to improve surgeons ability to } \\
\text { manage psychological stress should not be ignored as it would help surgeons perform better in challenging clinical situations. With the development of computer } \\
\text { technology, increasingly more advanced digital processors and design features will help surgeons achieve better performance. LPD training programs should be } \\
\text { established at large-volume pancreatic centers with a protocol in place to certify appropriately trained surgeons }\end{array}$ & Moderate & Strong \\
\hline & 16 & $\begin{array}{l}\text { Management of } \\
\text { the learning curve }\end{array}$ & $\begin{array}{l}\text { Surgeons achieve technical competency after performing } 30 \text { to } 50 \text { LPD procedures. Operation time, intraoperative blood loss, conversion, postoperative } \\
\text { complication rate, and LOS are the indicators to be used for learning curve assessment }\end{array}$ & Moderate & Strong \\
\hline
\end{tabular}

LPD, laparoscopic pancreaticoduodenectomy; OPD, open pancreaticoduodenectomy; LOS, length of stay; MDT, multidisciplinary team. 